\title{
ANÁLISE DOS MARCADORES DE CÉLULAS TRONCO TUMORAIS EM LINHAGENS TUMORAIS RESISTENTES AO ESTRESSE
}

Versão Original

Tese apresentada ao Programa de Pós-graduação em Biologia Celular e Tecidual do Instituto de Ciências Biomédicas da Universidade de São Paulo para a obtenção do título de Doutor em Ciências (Biologia de Sistemas).

Área de concentração: Biologia Celular e Tecidual

Orientadora: Profa. Dra. Vanessa Morais Freitas

São Paulo 


\section{RESUMO}

RALPH, Ana Carolina Lima. Análise dos marcadores de células tronco tumorais em linhagens tumorais resistentes ao estresse. 2019. 130 f. Tese (Doutorado em Biologia Celular e Tecidual) - Instituto de Ciências Biomédicas da Universidade de São Paulo, São Paulo, 2019.

Tumores sólidos, tais como câncer de mama, possuem um microambiente particularmente hostil devido a perfusão sanguínea insuficiente, supressão de células regulatórias, distúrbios metabólicos, dentre outros fatores que dificultam as terapias antitumorais. Células epiteliais adaptadas à essas condições, passam por uma seleção natural, adquirindo características que favorecem diretamente a progressão tumoral. Apesar de muitos estudos terem demonstrado diferenças importantes entre o interstício da célula tumoral e o da célula normal, as funções celulares nessas condições permanecem pouco conhecidas. Levando em consideração a significância do microambiente na progressão do câncer, esse estudo visou avaliar a capacidade da acidose, da baixa concentração de glicose e da hipóxia em modular genes, proteínas e o comportamento celular na transição epitélio-mesenquimal (TEM) e no fenótipo tronco tumoral. No presente estudo foram utilizadas as linhagens de adenocarcinoma mamário MDA-MB231 e MCF7, além da NTERA2 e fibroblastos, para controle positivo e cultivo tridimensional, respectivamente. A partir dos resultados de viabilidade celular, as linhagens tumorais foram expostas a três condições ambientais restritivas: (1) cultivo com $\mathrm{pH} 6,2$ durante $24 \mathrm{~h}$ ou a cada $72 \mathrm{~h}$ por 4 semanas, de forma a reproduzir as condições agudas e crônicas do microambiente ácido; (2) metade da concentração de glicose (0,5 $\mathrm{g} / \mathrm{L}$ ), para reproduzir a privação de nutrientes; ou (3) tratamento com cloreto de cobalto $200 \mu \mathrm{M}$, para induzir hipóxia química. Os resultados iniciais demonstraram que 71,43\% dos genes relacionados ao fenótipo tronco foram diferencialmente expressos na MDAMB-231, enquanto que na MCF7 foram apenas 23,81\%. No entanto, constatou-se que a linhagem MCF7, passa por um processo anterior ao fenótipo tronco. Após exposição ao pH 6.2, ela passa de um fenótipo epitelial para mesenquimal, demonstrando expressão de diversos marcadores de TEM (Snai1, Zeb1, E-caderina, $\beta$-catenina e vimentina). No entanto, a expressão de marcadores proteicos de fenótipo tronco só se tornam significante quando é associado a ausência de substrato. A adição de mais um fator estressante altera 
inclusive o potencial migratório e clonogênico das MCF7. Por outro lado, a linhagem MDA-MB-231 apresentou-se mais sensível a deficiência de glicose. A condição de glicose $0,5 \mathrm{~g} / \mathrm{L}$ induziu alterações na expressão de proteínas metabólicas (p-AMPK e AMPK), importantes alterações morfológicas mitocondriais e em proteínas responsáveis pela dinâmica mitocondrial (p-DRP1, DRP1, MFN1, MFN2). Tal sensibilidade à privação de glicose contribui significativamente para o aumento gênico e proteico de marcadores para o fenótipo tronco (Snail, Nanog, Pou5f1/Oct4, Notch1) e enriquecimento da população celular $\mathrm{CD} 44^{+} / \mathrm{CD} 24^{-/ \text {low }}$. Apesar de não ter sido encontrado alterações funcionais importantes na migração e clonogenicidade, assim como na MCF7 em condições acídicas, a MDA-MB-231 quando cultivada na forma tridimensional e na presença de fibroblastos, consegue induzir o aumento na migração de fibroblastos na glicose $0,5 \mathrm{~g} / \mathrm{L}$. Os resultados aqui apresentados contribuem para o entendimento de em quê cada fator microambiental pode influenciar nas alterações fenotípicas celulares e realça a importância da associação intercelular como forma de colaborar para a progressão do tumor.

Palavras-chave: Microambiente tumoral. Reprogramação metabólica. Heterogeneidade tumoral. Plasticidade tumoral. Acidose. Privação de glicose. Hipóxia. 


\begin{abstract}
Solid tumors, such as breast cancer, have a particularly hostile microenvironment due to insufficient blood perfusion, regulatory cell suppression, metabolic disorders, among other factors that hamper antitumor therapies. Epithelial cells adapted to these conditions, go through a natural selection, acquiring characteristics that directly favor the tumor progression. Although many studies have shown important differences between the interstitium of the tumor cell and that of the normal cell, cellular functions under these conditions remain poorly understood. Taking into account the significance of the microenvironment in the progression of cancer, this study aimed to evaluate the capacity of acidosis, low glucose concentration and hypoxia in modulating genes, proteins and cellular behavior in the epithelial-mesenchymal transition (EMT) and cancer stem cell phenotype. In the present study, mammary adenocarcinoma MDA-MB-231 and MCF7, as well as NTERA2 and fibroblasts, were used for positive control and three-dimensional culture, respectively. From the cell viability results, tumor cell lines were exposed to three restrictive environmental conditions: (1) culture at $\mathrm{pH} 6.2$ for $24 \mathrm{~h}$ or every $72 \mathrm{~h}$ for 4 weeks, in order to reproduce the acute and chronic conditions of the acidic microenvironment; (2) low glucose concentration $(0.5 \mathrm{~g} / \mathrm{L})$, to reproduce nutrient deprivation; or (3) treatment with $200 \mu \mathrm{M}$ cobalt chloride to induce chemical hypoxia. The initial results showed that $71.43 \%$ of the genes related to the stem phenotype were differentially expressed in the MDA-MB-231, whereas in the MCF7 they were only $23.81 \%$. However, it was verified that the lineage MCF7, goes through a process previous to the stem cell phenotype. After exposure to $\mathrm{pH} 6.2$, it changes from an epithelial to mesenchymal phenotype, demonstrating the expression of several EMT markers (Snai1, Zeb1, E-cadherin, $\beta$-catenin and vimentin). However, the expression of protein markers of stem phenotype only become significant when it is associated with absence of substrate (3D culture). The addition of one more stress factor alters even the migratory and clonogenic potential of MCF7. On the other hand, the MDA-MB-231 strain was more sensitive to glucose deficiency. The glucose concentration of $0.5 \mathrm{~g} / \mathrm{L}$ induced alterations in the expression of metabolic proteins ( $\mathrm{p}$-AMPK and AMPK), important mitochondrial morphological alterations and proteins responsible for mitochondrial dynamics (p-DRP1, DRP1, MFN1, MFN2). Such sensitivity to glucose deprivation contributes significantly
\end{abstract}


to the gene and protein increase of cancer stem cell markers (Snai1, Nanog, POU5F1/Oct4, Notch1) and enrichment of the $\mathrm{CD} 44^{+} / \mathrm{CD} 24^{-/ \text {low }}$ cell population. Although important functional changes in migration and clonogenicity have not been found, as well as in MCF7 under acidic conditions, MDA-MB-231 when cultured in three-dimensional in the presence of fibroblasts induce the increase in the migration of fibroblasts in glucose $0.5 \mathrm{~g} / \mathrm{L}$ condition. The results presented here contribute to the understanding of how each microenvironmental factor can influence cellular phenotypic alterations and highlights the importance of the intercellular association as a way of collaborating for tumor progression.

Key words - Tumor microenvironment. Metabolic reprograming. Tumor heterogeneity. Tumor plasticity. Acidosis. Glucose deprivation. Hypoxia. 


\section{INTRODUÇÃO E OBJETIVOS GERAIS}

\subsection{INTRODUÇÃO GERAL}

Apesar de muito ser conhecido sobre os fatores do microambiente que influenciam na progressão tumoral, pouco é conhecido sobre a influência desses fatores isoladamente, na exposição aguda ou crônica ao estímulo, e ainda qual a sua influência sobre a população celular com fenótipo tronco tumoral. Desse modo, o presente estudo procurou avaliar alguns efeitos fenotípicos e funcionais da hipóxia, da privação de glicose e do $\mathrm{pH}$ ácido sobre linhagens celulares de câncer de mama humano.

Esta tese foi didaticamente dividida em 5 capítulos. O capítulo 1 trata do referencial teórico que serviu como base para as perguntas do estão respondidas nos resultados apresentados dos capítulos 2 ao 4 . O capítulo 2 retrata os resultados iniciais obtidos após a avaliação da indução da hipóxia, acidose e baixa glicose em células de câncer de mama. Tais resultados guiaram o potencial fenotípico tronco tumoral nessas condições. $\mathrm{O}$ capítulo 3 aborda os efeitos causados pela exposição das células de câncer de mama à baixa concentração de glicose, apontando a pressão adaptativa causada por essa condição como um importante contribuinte para o desenvolvimento do fenótipo tronco tumoral e para alterações na relação da célula do câncer de mama com outras células que compõem o microambiente, tais como o fibroblasto. $\mathrm{O}$ capítulo 4 mostra o papel da acidose sobre o processo da transição epitélio-mesenquimal e seus efeitos sobre o desenvolvimento do fenótipo tronco e o comportamento celular frente a outros fatores microambientais. Por fim, o capítulo 5 apresenta as conclusões alcançadas e considerações finais.

Os parágrafos seguintes demonstram o que tem sido feito atualmente pela comunidade científica em relação aos tópicos: câncer, câncer de mama, reprogramação metabólica, metabolismo e microambiente tumoral, hipóxia, privação de glicose, acidose e dinâmica mitocondrial. 


\subsubsection{Câncer}

O câncer compreende um conjunto de doenças que se caracterizam pela presença de células em crescimento contínuo e descontrolado. O tumor é um tecido complexo composto por múltiplos tipos celulares que participam de interações heterotípicas de forma a contribuir para o desenvolvimento de capacidades inerentes do tecido tumoral. Dentre essas características destaca-se: sinalização celular sustentada, com produção de fatores de crescimento resultando em estimulação proliferativa autócrina; instabilidade genômica; evasão de supressores de crescimento; indução de angiogênese; ativação da invasão e metástase (HANAHAN; WEINBERG, 2011).

A carcinogênese é um processo complexo, multifatorial, frequentemente descrito como uma "evolução somática", em que a somatória dos fatores carcinogênicos suprimem os mecanismos de proteção celular para desencadear o desenvolvimento da doença (GATENBY; GILLIES, 2008). Pelo conceito clássico, a carcinogênese é a transformação de uma célula normal em maligna através de não apenas uma, mas sim uma série de alterações genéticas. Essas alterações envolvem: mutações que ativam oncogenes (genes capazes de induzir a formação do tumor), mutações que inativam supressores de tumor (genes capazes de inibir a formação do tumor), ou ainda inativação da estabilidade gênica, que é capaz de causar a mutação de outros genes associados (COSTELLO; FRANKLIN, 2012). 


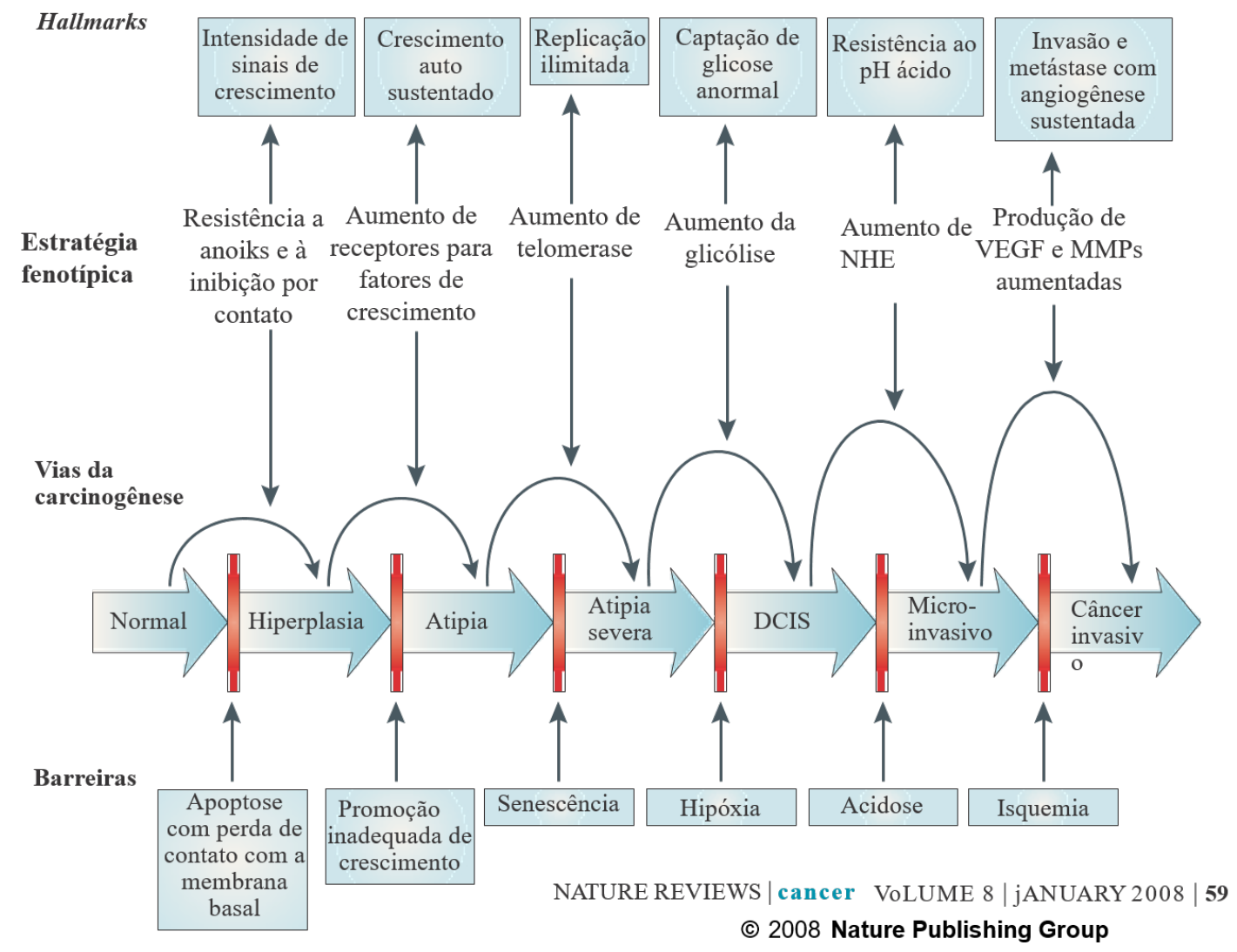

Figura 1 - Barreiras propostas para a carcinogênese. Estratégia fenotípica para cada barreira está mostrada ao longo dos hallmark. As setas curvadas refletem as populações de células em crescimento. A sequência específica de barreiras está baseada nas mudanças no panorama adaptativo de lesões pré malignas. DCIS - carcinoma ductal in situ; MMP - metaloproteinase de matriz; NHE - trocador $\mathrm{Na}+/ \mathrm{H}+$; VEGF - fator de crescimento endotelial vascular. Adaptado de: GATENBY; GILLIES, 2008.

O processo carcinogênico envolve três etapas cruciais: iniciação, desenvolvimento e progressão. A iniciação se caracteriza pela indução de uma mudança em uma célula na qual a mesma se torna neoplásica e adquire uma vantagem seletiva de crescimento sobre as células adjacentes normais (NOWELL, 1976). As primeiras adaptações fenotípicas decorrentes das mudanças genéticas causadas pelo processo carcinogênico são inibição de morte celular e do controle da proliferação por perda inibição por contato (GATENBY; GILLIES, 2008).

De forma progressiva, a fase de desenvolvimento se caracteriza fenotipicamente pela transição de um epitélio normal (formado por células conectadas umas as outras e com a membrana basal) para um epitélio displásico (epitélio formado por células em crescimento desordenado). A instabilidade genômica adquirida, leva ao estabelecimento da doença. Para conseguir continuar crescendo, as células tumorais adquirem novas características migratórias (câncer micro invasivo) e invasivas (câncer invasivo), possibilitando sua passagem através da membrana basal e seu desenvolvimento em outros 
tecidos do corpo, configurando a metástase e a progressão tumoral (COSTELLO; FRANKLIN, 2012).

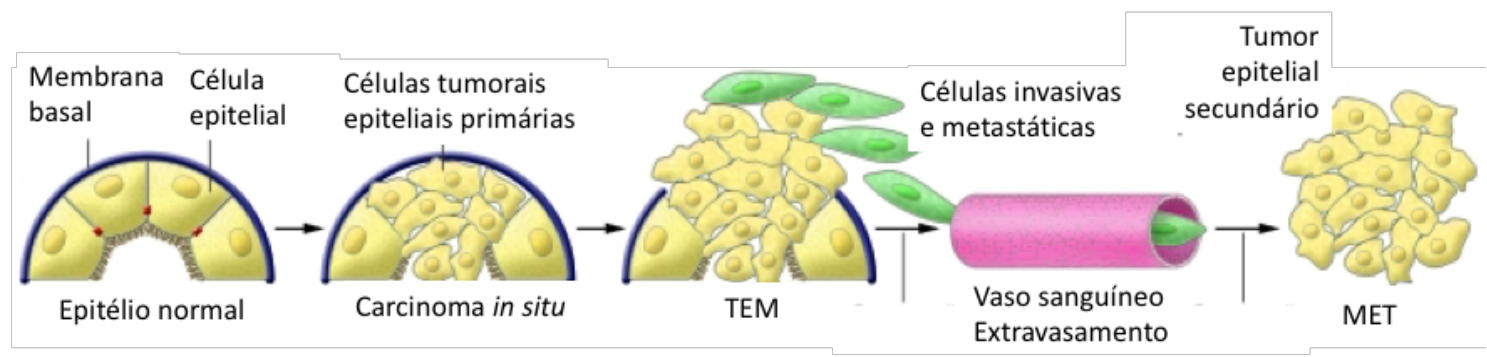

Figura 2 - Progressão tumoral - Iniciação através de um estímulo carcinogênico, seguido de proliferação exacerbada caracterizando o carcinoma in situ. Posteriormente, as células neoplásicas adquirem a capacidade de invadir a membrana basal, caindo na corrente sanguínea a podendo dar origem a sítios tumorais secundários através do estabelecimento da metástase tumoral. Adaptado de: Kalluri e Weinberg (2009). TEM: transição epitélio-mesenquimal, MET- transição mesênquima-epitelial (KALLURI; WEINBERG, 2009).

O aumento na capacidade migratória e invasiva em células epiteliais é decorrente do processo transitório denominado transição epitélio-mesenquimal (TEM). Nesse processo, células epiteliais, que possuem características de células justapostas, conectadas por complexos juncionais com a célula vizinha e com a membrana basal, perdem a conexão por meio dessas proteínas de adesão e passam a sobreviver de forma isolada, estando mais livres para migrar e invadir para outros tecidos (KALLURI; WEINBERG, 2009; THIERY et al., 2009).

A interface de transição entre o fenótipo de um carcinoma in situ para um carcinoma invasivo é determinada pela expressão de marcadores moleculares específicos. Durante a TEM, as células perdem a expressão de marcadores epiteliais, tais como Ecaderina, e passam a expressar marcadores mesenquimais, tais como vimentina. A transição na expressão desses marcadores é regulada por fatores de transcrição (“drivers") tais com SNAIL (SNAI1) (GUAITA et al., 2002; PEINADO; OLMEDA; CANO, 2007), ZEB1 e ZEB2 (SÁNCHEZ-TILLÓ et al., 2010), TWIST1 que são responsáveis por reprimir, direta ou indiretamente, a expressão de proteínas de adesão, principalmente a E-caderina (LAMOUILLE; XU; DERYNCK, 2014; THIERY et al., 2009). 


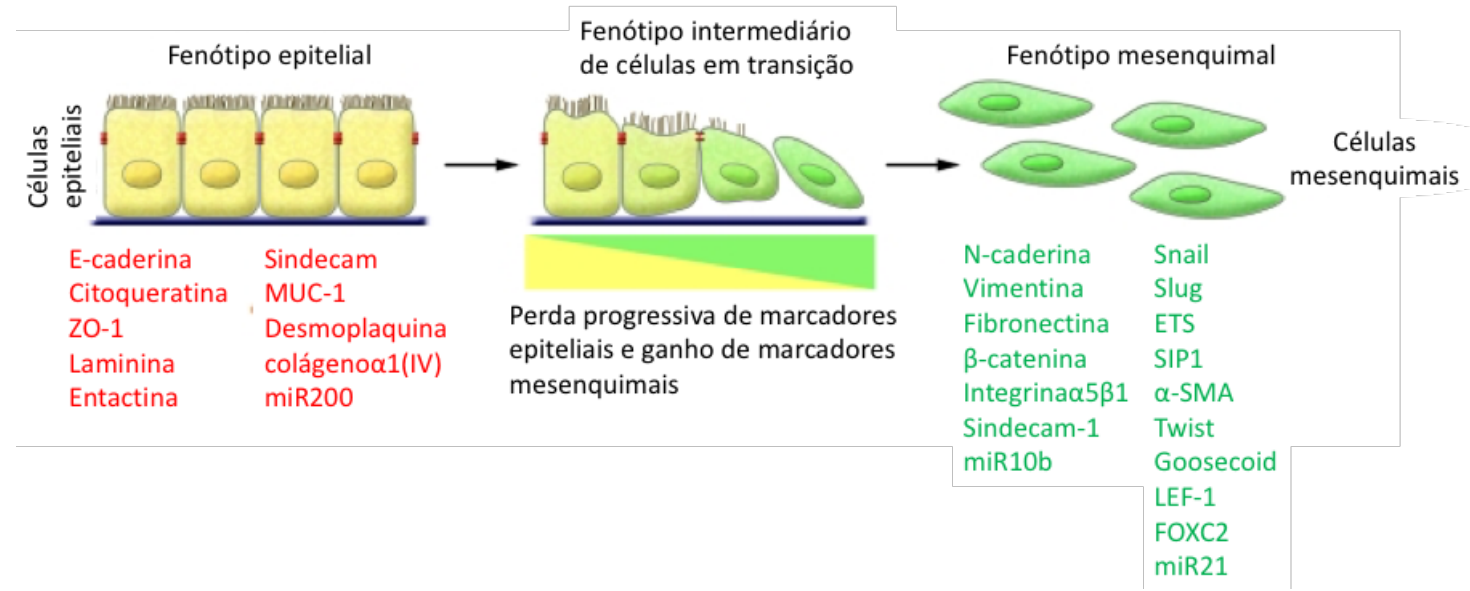

Figura 3 - Processo de transição epitélio-mesenquimal - Esse processo ocorre pela transição de um fenótipo epitelial, com expressão de marcadores principalmente relacionados a adesão célula-célula e célula-membrana basal, para um fenótipo mesenquimal, em que as células caracteristicamente mais isoladas e independentes, expressam marcadores Adaptado de: Kalluri e Weinberg (2009). TEM: transição epitélio-mesenquimal, MET- transição mesênquima-epitelial.

Coletivamente, o processo carcinogênico pode evoluir para o aparecimento de tumores mais agressivos, com capacidade de invadir outros tecidos, o que contribui para tumores resistentes a quimioterapia padrão, com mau prognóstico e alto índice de recidivas. Tais fatores justificam os dados apresentados abaixo em relação as estatísticas do câncer no mundo e no Brasil.

\subsubsection{Estatísticas do câncer}

No mundo, de acordo com a Agência mundial de pesquisa para o câncer, são estimadas 18,1 milhões de novos casos e 9,6 milhões de mortes causadas por câncer (BRAY et al., 2018; FERLAY et al., 2019) para o ano de 2019. Para o Brasil, no entanto, estima-se a ocorrência de 600 mil novos casos de câncer para cada ano do biênio 2018 2019. Essas estimativas refletem o perfil de um país que possui câncer de próstata, pulmão, mama feminina e cólon e reto entre os mais incidentes, entretanto ainda apresenta altas taxas para câncer de colo do útero, estômago e esôfago (INCA, 2017).

Nesse panorama, o câncer de mama se destaca, apresentando os maiores índices de incidência e letalidade do mundo e do Brasil em mulheres. Ao redor do mundo foram esperados 2,1 milhões de novos casos de câncer de mama para 2018, sendo o mesmo responsável por cerca de 1 a cada 4 novos casos de câncer em mulheres. $\mathrm{O}$ câncer de mama é a doença mais frequentemente diagnosticada em mulheres na maioria dos países (154 de 185), sendo também a causa mais frequente de mortes por câncer (BRAY et al., 2018; FACTS, 2019; SIEGEL; MILLER; JEMAL, 2019). 
Para o Brasil estimam-se 59.700 novos casos de câncer de mama para o biênio 2018-2019, com risco estimado de 56,33 casos a cada 100 mil mulheres. Sem considerar os tumores de pele não melanoma, esse tipo de câncer também é o primeiro mais frequente nas mulheres brasileiras, destacando sua incidência alta nas regiões sul $(73,07 / 100 \mathrm{mil})$, sudeste $(69,50 / 100 \mathrm{mil})$, centro-oeste $(51,96 / 100 \mathrm{mil})$ e nordeste. $\mathrm{Na}$ região norte é o segundo tumor mais incidente (19,21/100 mil), perdendo apenas para o câncer de colo de útero (25,62/100 mil) (INCA, 2017).

\begin{tabular}{|c|c|c|c|c|c|}
\hline \multicolumn{6}{|l|}{ Novos casos mundiais estimados } \\
\hline A. & & & Mulheres & & \\
\hline Próstata & 174,650 & $20 \%$ & Mama & 268,600 & $30 \%$ \\
\hline Pulmão e brônquios & 116,440 & $13 \%$ & Pulmão e brônquios & 111,710 & $13 \%$ \\
\hline Cólon e reto & 78,500 & $9 \%$ & Cólon e reto & 67,100 & $8 \%$ \\
\hline Bexiga urinária & 61,700 & $7 \%$ & Corpo uterino & 61,880 & $7 \%$ \\
\hline Melanoma de pele & 57,220 & $7 \%$ & Melanoma de pele & 39,260 & $4 \%$ \\
\hline Rins e pelve renal & 44,120 & $5 \%$ & Tireoide & 37,810 & $4 \%$ \\
\hline Linfoma non-Hodgkin & 41,090 & $5 \%$ & Linfoma non-Hodgkin & 33,110 & $4 \%$ \\
\hline Cavidade oral e faringe & 38,140 & $4 \%$ & Rins e pelve renal & 29,700 & $3 \%$ \\
\hline Leucemia & 35.920 & $4 \%$ & Pâncreas & 26,830 & $3 \%$ \\
\hline Pâncreas & 29,940 & $3 \%$ & Leucemia & 25,860 & $3 \%$ \\
\hline Todos os sítios & 870,970 & $100 \%$ & Todos os sítios & 891,480 & $100 \%$ \\
\hline
\end{tabular}

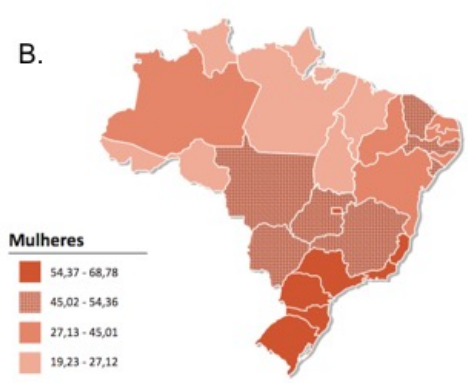

Figura 4 - Estatísticas do câncer de mama - A. Estimativa dos 10 tipos de câncer mais incidentes para 2019 de acordo com a Sociedade Americana do Câncer (Adaptado de Cancer Facts and Figures, 2019); B. Representação espacial das taxas ajustadas de incidência de neoplasia maligna da mama feminina por 100 mil mulheres, estimadas para o biênio 2018-2019, segundo Unidade da Federação (Adaptado de INCA, 2018).

\subsubsection{Câncer de mama}

A estrutura da glândula mamária normal depende da presença de três células epiteliais distintas: (1) células luminais do ducto, que formam a camada do epitélio de revestimento do ducto; (2) células luminais alveolares, que são as células responsáveis pela síntese do leite materno; (3) células mioepiteliais, que circundam as células luminais alveolares e, através das suas propriedades contráteis, possibilitam a ejeção do leite. Todos esses tipos celulares são amadurecidos durante a puberdade e a fase adulta, pois o desenvolvimento da glândula mamária é um evento pós-natal (HENNIGHAUSEN; ROBINSON, 2005). 


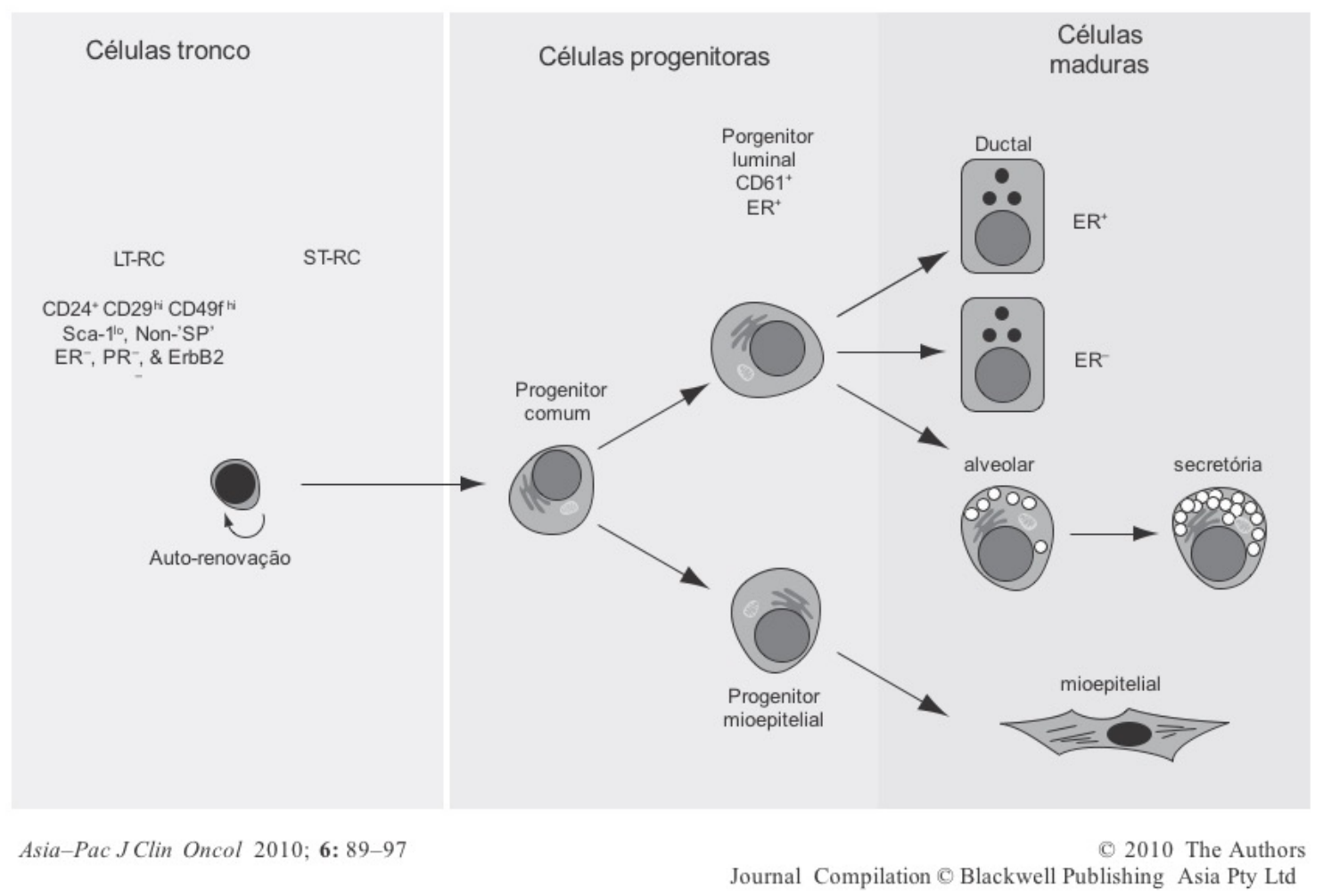

Figura 5 - Constituição celular básica da glândula mamária - $\mathrm{O}$ tecido mamário pode ser constituído de pelo menos três subtipos celulares que se diferenciam de forma hierárquica a partir de uma célula tronco comum estimulado por hormônios específicos. ER - Receptor de Estrogênio; ST-RC - short term repopulating cell (célula de repopulação de curto prazo). Adaptado de: LINDEMAN; VISVADER, 2010.

Os primeiros estudos sobre o câncer de mama demonstraram que em uma mesma amostra de tumor pode haver até 127 genes que sofreram mutação. Tal informação realça a intensa heterogeneidade desses tumores. A natureza heterogênea dos tumores de mama leva a uma variedade de subtipos, comportamentos e respostas terapêuticas, que afetam significativamente o prognostico individual dos pacientes. Essa variabilidade pode acontecer de uma população para outra, entre células fenotipicamente diferentes dentro do mesmo tumor, ou até durante o crescimento tumoral e na resposta ao tratamento (PECE et al., 2010; SHIPITSIN et al., 2007).

Entre os anos 2000 e 2001, pesquisadores usaram análise de expressão gênica para determinar subtipos moleculares de câncer de mama. Tal classificação colabora para predizer prognóstico e resposta do paciente a terapias. Os primeiros subtipos identificados foram: normal-like, luminal $\mathrm{A}$, luminal $\mathrm{B}$, basal-like e ERBB2-positivo (também denominado HER2 enriquecido). Posteriormente, o tipo normal-like foi eliminado e o subtipo triplo-negativo e claudina-low foram adicionados à nova classificação (HERSCHKOWITZ et al., 2007; LINDEMAN; VISVADER, 2010). 
Atualmente os tumores de mama podem ser molecularmente classificados em cinco subtipos, de acordo com características moleculares particulares, tais como: expressão de receptores para estrogênio e/ou progesterona (ER, PR), expressão de receptores para fator de crescimento epidérmico (HER2/ERBB2/NEU) e expressão de proteínas de adesão célula-célula e junções tight. O primeiro subtipo apresenta receptores para estrogênio e/ou progesterona, dois subtipos não apresentam expressão de receptor para estrogênio (ER-negativo), o terceiro subtipo apresenta alta expressão de HER2/ERBB2/NEU, o quarto subtipo apresenta características basais ou de células mioepiteliais (basal-like) enquanto o quinto subtipo apresenta deficiência ou ausência na expressão de proteínas de adesão célula-célula e célula-membrana basal (HERSCHKOWITZ et al., 2007).

Tabela 1 - Subtipos moleculares de câncer de mama (modificado de Odle, 2017).

\begin{tabular}{|c|c|c|}
\hline SUBTIPO & ERFIL MOLECULAR & CARACTERÍSTICAS PRINCIPAIS \\
\hline Luminal A & ER+/PR+/HER2-/Ki67- & $\begin{array}{l}\text { Tumor de baixo grau associado a baix } \\
\text { recorrência e bom prognóstico }\end{array}$ \\
\hline $\begin{array}{l}\text { Luminal B } \\
(\text { her2-ou+) }\end{array}$ & R+/PR+/HER2-ou+/Ki67+ & $\begin{array}{l}\text { Tumor de alto grau associado a alt } \\
\text { recorrência e prognóstico pior que o tip } \\
\text { luminal A }\end{array}$ \\
\hline HER2+ & ER-/PR-/HER2+ & $\begin{array}{l}\text { Frequentemente encontrado en } \\
\text { carcinomas ductais in situ associados } \\
\text { baixa sobrevida }\end{array}$ \\
\hline $\begin{array}{l}\text { Triplo } \\
\text { negativo ou } \\
\text { basal-like }\end{array}$ & $\begin{array}{l}\text { ER-/PR-/HER2-/marcadores } \\
\text { basais }+\end{array}$ & $\begin{array}{l}\text { Sobreposição entre tumores basal-like } \\
\text { triplo negativo associados a ma } \\
\text { prognóstico }\end{array}$ \\
\hline Claudina-low & $\begin{array}{l}\text { Triplo negativo associado a } \\
\text { baixa expressão de proteínas de } \\
\text { adesão célula-célula claudina, } \\
\text { ocludina e E-caderina }\end{array}$ & $\begin{array}{l}\text { Tumores de alto grau, com infiltras } \\
\text { ductal, expressam marcado } \\
\text { mesenquimais com baixa expressão } \\
\text { proteínas de adesão epiteliais }\end{array}$ \\
\hline
\end{tabular}

ER - receptor de estrogênio; PR - receptor de progesterona; HER2 - receptor de fator de crescimento epidérmico, sinônimo de ERBB2 e NEU; Ki67 proteína marcadora de proliferação celular (LIM et al., 2010; ODLE, 2017).

Novos avanços no diagnóstico e no tratamento tem levado a abordagens cada vez mais personalizadas e individualizadas, denominada medicina de precisão (ODLE, 2017). O câncer de mama se destaca nessas abordagens por ser pioneiro na descoberta de marcadores específicos, tais como receptor de fator de crescimento epidérmico (ERBB2 ou HER2 ou HER/NEU) que possui terapia específica (inibidor específico de HER2). Esse aprimoramento marca o uso de conhecimentos sobre a especificidade genômica a favor do tratamento contra o câncer de mama, possibilitando o aprimoramento na qualidade de vida e sobrevida dos pacientes (CELIS et al., 2004; MARCINKOWSKA; STAŃCZYK; KLAJNERT-MACULEWICZ, 2015; RAKHA; CHAN, 2011). 
Cerca de 5\%-10\% dos cânceres de mama são do tipo hereditário. Dentre estes, $30 \%$ dos casos são causados por mutações nos genes BRCA1 e/ou BRCA2. BRCA1 e $B R C A 2$ codificam proteínas supressoras tumorais, essenciais para o reparo do DNA e à instabilidade genômica. A presença dessas mutações aumenta o risco de desenvolvimento de câncer de mama. Para tanto tem se intensificado novas técnicas de detecção precoce dessas mutações e isso tem contribuído de forma significativa para a diminuição da incidência da doença em pessoas com histórico familiar (SERRATÌ et al., 2016).

Além do fator de risco genético e hereditário (BRCA1, BRCA2 dentre outras mutações), as maiores taxas de incidência do câncer de mama estão relacionadas a: menarca precoce ou menopausa tardia, problemas reprodutivos (nulíparas, idade alta para a $1^{\text {a }}$ gravidez, poucos filhos), consumo hormonal exógeno (contraceptivos orais ou reposição hormonal), consumo de álcool e a antrometria (sobrepeso, má distribuição de gordura corporal). A amamentação e a prática de exercícios físicos são considerados fatores de proteção (BRAY et al., 2018; FACTS, 2019; SIEGEL; MILLER; JEMAL, 2019).

O tratamento padrão para os tumores de mama é variável e geralmente se utiliza mais de uma forma de tratamento para o mesmo paciente. $\mathrm{O}$ tratamento pode envolver cirurgia, quimioterapia (antes ou depois da cirurgia), hormonioterapia (antiestrogênicos), e terapia alvo, dependendo do estágio, do subtipo e dos benefícios de cada componente do tratamento (FACTS, 2019).

Através da identificação de marcadores moleculares específicos, tem sido possível planejar a realização do tratamento menos pelo sítio anatômico e mais por alvos moleculares específicos. Mesmo com o progresso no desenvolvimento de novos medicamentos, muitas pesquisas novas tem sido desenvolvidas para desenvolvimento de medicamentos mais precisos e menos danosos a qualidade de vida dos pacientes. Nesse sentido, os top 10 estudos clínicos atuais mostram principalmente estudos de associações de medicamentosas para tratamento de câncer de mama metastático HER2-negativo, assim como estudo de avaliações cognitivas durante o tratamento, além de avaliação de novas formas de rastreamento da doença para prevenção de recidivas e aumento no tempo de remissão (U.S. NATIONAL LIBRARY OF MEDICINE, 2019). 
Tabela 2 - Top 10 ensaios clínicos realizados para tratamento do câncer de mama

\begin{tabular}{|c|c|c|c|c|}
\hline & $\begin{array}{l}\text { NÚMERO } \\
\text { NTC }\end{array}$ & TÍTULO DO ENSAIO & STATUS & INTERVENÇÃO \\
\hline 1 & NCT03887130 & $\begin{array}{l}\text { Study of Oral Vinorelbine Plus } \\
\text { Capecitabine Versus Taxane- } \\
\text { gemcitabine Combinations as } \\
\text { 1st Line Chemotherapy in } \\
\text { Metastatic Breast Cancer }\end{array}$ & Fase 2 & $\begin{array}{l}\text { Vinorelbina oral com } \\
\text { Capecitabina e } \\
\text { Gemcitabine } \\
\mathrm{mg} / \mathrm{m} 2 \\
\text { Gemcitabine } \\
\mathrm{mg} / \mathrm{m} 2 \text { ou Paclitaxel } \\
\text { ou Docetaxel }\end{array}$ \\
\hline 2 & NCT03888677 & $\begin{array}{c}\text { Dose-adjusted Adjuvant FEC } \\
\text { Compared to Standard FEC for } \\
\text { Breast Cancer }\end{array}$ & Fase 3 & $\begin{array}{ll}\text { Associação de } & \text { 5- } \\
\text { Fluouracila, } & \\
\text { Epirrubicina } & \text { e } \\
\text { Ciclofosfamida } & \end{array}$ \\
\hline 3 & NCT02303145 & $\begin{array}{c}\text { Breast Cancer Survivorship \& } \\
\text { Work-Related Cognitive } \\
\text { Limitation }\end{array}$ & - & $\begin{array}{l}\text { Avaliação } r \text { das } \\
\text { limitações cognitivas } \\
\text { em pacientes com } \\
\text { câncer de mama }\end{array}$ \\
\hline 4 & NCT02443428 & $\begin{array}{c}\text { Eribulin Use for the Treatment } \\
\text { of Advanced Breast Cancer: A } \\
\text { Prospective Observational } \\
\text { Registry }\end{array}$ & - & Uso de Eribulina \\
\hline 5 & NCT01830933 & $\begin{array}{l}\text { Breast Cancer Risk Reduction: } \\
\text { A Patient Doctor Intervention }\end{array}$ & - & $\begin{array}{l}\text { Efeito do intervalo } \\
\text { entre o rastreio do } \\
\text { câncer em relação a } \\
\text { sobrevivência e o } \\
\text { período sem a doença }\end{array}$ \\
\hline 6 & NCT03165006 & $\begin{array}{c}\text { Effect of Interval Cancer and } \\
\text { Screening Process on Survival } \\
\text { and Disease-free Period in } \\
\text { Breast Cancer }\end{array}$ & - & \\
\hline 7 & NCT01750164 & $\begin{array}{c}\text { Patient Derived Breast Cancer } \\
\text { Xenografts }\end{array}$ & - & $\begin{array}{l}\text { Procedimento para } \\
\text { modo de detecção por } \\
\text { rastreamento ou } \\
\text { intervalo do câncer }\end{array}$ \\
\hline 8 & NCT02297230 & $\begin{array}{l}\text { Locally Advanced Breast } \\
\text { Cancer: Individualized } \\
\text { Treatment Based On Tumor } \\
\text { Molecular Characteristics }\end{array}$ & $\begin{array}{c}\text { Fase } 1 \mathrm{e} \\
2\end{array}$ & $\begin{array}{l}\text { Radioterapia } \\
\text { Capecitabina } \\
\text { Traztuzuman } \\
\text { Paclitaxel }\end{array}$ \\
\hline 9 & NCT01224678 & $\begin{array}{l}\text { Vitamin D and Breast Cancer } \\
\text { Biomarkers in Female Patients }\end{array}$ & Fase 3 & $\begin{array}{l}\text { Suplemento de } \\
\text { vitamina D ou placebo }\end{array}$ \\
\hline 10 & NCT02120417 & $\begin{array}{c}\text { A Study of Ruxolitinib in } \\
\text { Combination with Capecitabine } \\
\text { in Subjects With Advanced or } \\
\text { Metastatic HER2-negative } \\
\text { Breast Cancer }\end{array}$ & Fase 2 & $\begin{array}{l}\text { Ruxolitinib } \\
\text { Capecitabine } \\
\text { Placebo }\end{array}$ \\
\hline
\end{tabular}


Com o objetivo de detectar precocemente o câncer de mama, de forma a torna-lo mais facilmente curável, são realizados rastreamentos periódicos. Para tanto, normalmente utiliza-se o exame clínico associado a várias técnicas de imagem, tais como mamografia (convencional ou 3D, sendo que a 3D detecta 1,2 vezes mais cânceres invasivos a cada 1000 exames), ultrassonografia e ressonância magnética nuclear. A frequência recomendada para esses exames ainda está em constantes debates (PEAIRS et al., 2017; RAICHAND et al., 2017).

De acordo com Peairs e colaboradores (2017), o exame bienal tem sido o mais eficiente na idade entre 50 e 74 anos, com uma média de 7 mortes evitadas a cada 1000 exames realizados . Em comparado com o exame anual, o exame bienal diminui falsopositivo (1,988 menos falso positivos a cada 1000 mulheres examinadas), biopsias desnecessárias e diagnósticos errados (PEAIRS et al., 2017). Para Raichand e colaboradores (2017) a mamografia é uma das principais ferramentas de diagnóstico, dando suporte à rotina da prática clínica (RAICHAND et al., 2017). Vale ressaltar que tais procedimentos de rotina não servem para rastreio de grupos de alto risco (mulheres com mutação em $B R C A$, ou que sofreram contato intenso com radiação, ou que possuem histórico de câncer de mama familiar) (PEAIRS et al., 2017).

Apesar das crescentes informações sobre a biologia do câncer de mama, muito ainda será preciso entender a respeito do desenvolvimento do câncer de mama metastático. Cerca de 6\%-10\% de todos os cânceres de mama diagnosticados nos Estados Unidos estão no estágio IV, enquanto que cerca de $27 \%$ apresenta focos distantes da doença o que caracteriza tumores com alta mortalidade e baixas taxas de sobrevida (FACTS, 2019; LIM; HORTOBAGYI, 2016).

Alguns fatores contribuem significativamente para a progressão tumoral: (1) adaptação ao microambiente, nisso se inclui: capacidade de resistir a hipóxia, capacidade de resistir a deficiência de nutrientes e consequente acidose, capacidade de corromper células vizinhas para escapar da supressão imune, promover a angiogênese e degradar a matriz extracelular para possibilitar progressão (LEHUÉDÉ et al., 2016; QUAIL; JOYCE, 2013); (2) intensificação de comunicação intercelular por meio de liberação de interleucinas e vesículas extracelulares, preparando para a formação de um futuro nicho pré-metastático (GMBH, 2017). 


\subsubsection{Microambiente tumoral}

Modelos de carcinogênese são tipicamente baseados no princípio da evolução natural de Darwin em que a evolução requer mudanças genéticas e/ou epigenéticas para geração de um novo fenótipo. A dinâmica de Darwin consiste na interação de fenótipos individuais com as forças de seleção ambientais que governam a proliferação (GATENBY; VINCENT, 2003). No panorama adaptativo da evolução somática, as barreiras ambientais para proliferação representam forças seletivas cruciais para adquirir um novo fenótipo. Sendo assim, as mudanças fenotípicas que ocorrem durante a carcinogênese representam adaptações bem sucedidas as forças seletivas do ambiente (GATENBY; GILLIES, 2008).

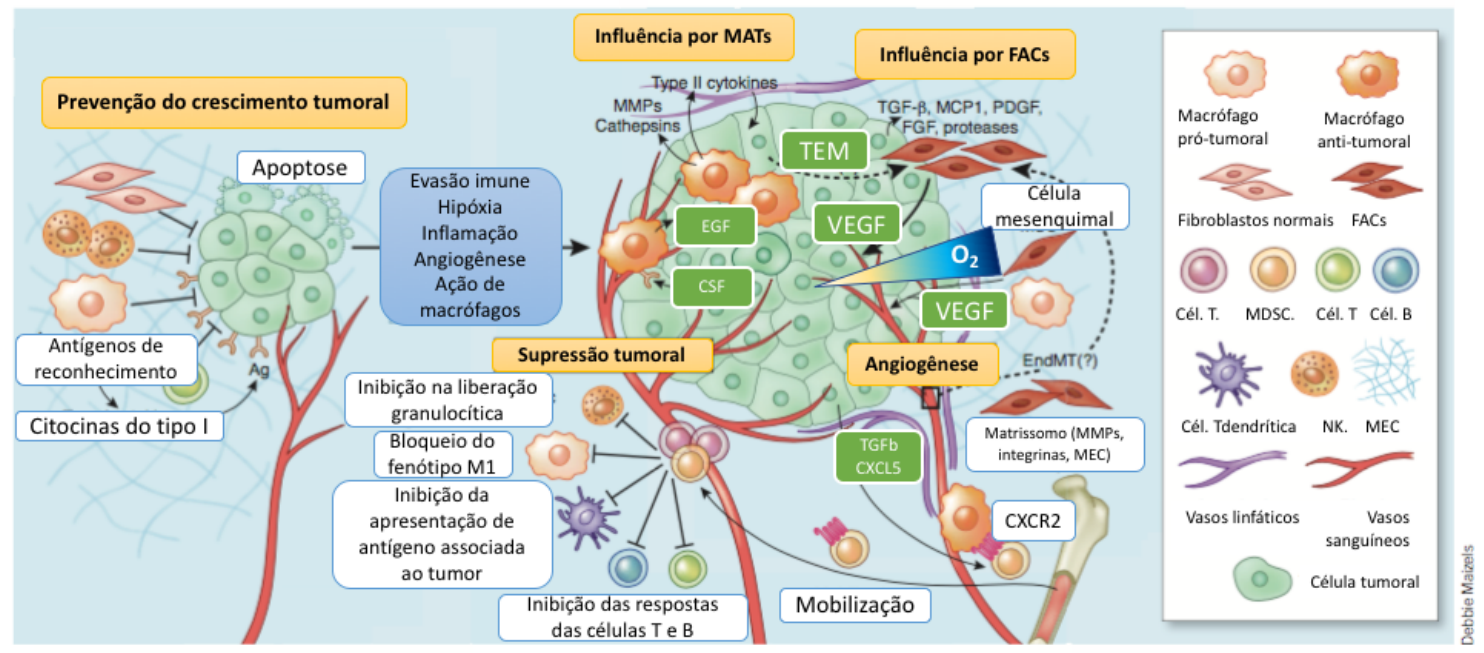

Figura 6 - Múltiplas células e substâncias sinalizadoras liberadas no microambiente convergem para suportar o nicho tumoral primário. EndMT, transição endotelial-mesenquimal; Ag, antígeno. Adaptado de QUAIL; JOYCE, 2013.

Ressalta-se que o fenótipo maligno tumoral não é apenas determinado pelas células neoplásicas em si, mas também pelo ambiente que as cerca. Esse microambiente inclui vários tipos celulares (fibroblastos, células inflamatórias, células epiteliais, células endoteliais e células mesenquimais), componentes da matriz extracelular, além de interleucinas e vesículas associados a um ambiente hipóxico, ácido e pobre em nutrientes (MARIE-CALINE Z. ABADJIAN, W. BARRY EDWARDS, 2012).

O estroma normal consiste no tecido conjuntivo que atua como suporte para tecidos e órgãos. Dentre todos os componentes estromais, os fibroblastos são essenciais para sintetizar e depositar a matriz extracelular, produzindo uma variedade de componentes. Funcionalmente, os fibroblastos contribuem tanto para a integridade da matriz extracelular e da membrana basal, quanto participam no processo de cicatrização e regeneração tecidual. Em resposta a estímulos inflamatórios e infecciosos, o estroma 
também recebe populações celulares transientes do sistema imune, responsáveis pela manutenção da integridade tecidual (MÜLLER; RODEMANN, 1991; SIMIAN et al., 2001).

Ao contornar os mecanismos celulares intrínsecos da apoptose, as células tumorais estão sujeitas a pressões de eliminação pelo sistema imunológico. Os antígenos específicos das células tumorais desempenham um importante papel durante este processo. As células imunitárias citotóxicas reconhecem esses antígenos causando a morte das células tumorais. Fibroblastos e macrófagos dentro do microambiente tumoral contribuem para um estado de supressão do crescimento, entretanto, essas células podem posteriormente ser "educadas" pelo tumor para adquirir funções pró-tumorigênicas (QUAIL; JOYCE, 2013).

Os macrófagos associados ao tumor (MAT) suportam diversos fenótipos dentro do tumor primário, incluindo crescimento, angiogênese e invasão, secretando uma gama de proteases pró-tumorigênicas, citocinas e fatores de crescimento (por exemplo, EGF, que participa de uma alça de sinalização parácrina). Adicionalmente, os fibroblastos associados ao câncer (FACs), que se tornam ativados por fatores derivados de tumores (por exemplo, TGF-b, FGF ou PDGF, entre outros), secretam proteínas da matriz extracelular (MEC) e componentes da membrana basal, regulam a diferenciação, modulam respostas imunes e contribuem para a homeostase desregulada (FRIDMAN, 2018; QIU et al., 2018; QUAIL; JOYCE, 2013).

Os FACs também são uma fonte importante do fator de crescimento endotelial (VEGF), que suporta a angiogênese durante o crescimento do tumor (QUAIL; JOYCE, 2013). Adicionalmente, co-cultura de célula tumoral com fibroblasto induz o crescimento de tumores de mama por promover o aumento vascular via mecanismo dependente de metaloproteinase-9 de forma a estimular a angiogênese por meio de interleucinas (LIMOGE et al., 2017).

Para mediar a comunicação célula-célula, células imunes ou do estroma produzem proteínas de baixo peso molecular, denominadas interleucinas. Tais moléculas são capazes de regular a proliferação, sobrevivência, diferenciação, migração, ou até morte celular (ZAMARRON; CHEN, 2011). Existem várias interleucinas pró-inflamatórias, dentre elas, a interleucina-6 (IL-6) se destaca pelo seu efeito tumorigênico (HODGE; HURT; FARRAR, 2005), sendo inclusive capaz de induzir a formação e manutenção de células tronco de câncer de mama (ILIOPOULOS et al., 2011), além de induzir TEM e aumentar a capacidade invasiva das células (SULLIVAN et al., 2009). Da mesma forma, 
a interleucina-8 (IL-8) é responsável pelo aumento da proliferação, migração e estímulo da angiogênese, além de acelerar o processo de transição epitélio-mesenquimal em células tumorais (NING et al., 2011). A interleucinas-1 $\beta$ (IL-1 $\beta$ ), de forma similar, também está relacionada ao aumento no potencial invasivo em carcinomas mamários (JIN et al., 1997).

Assim como as interleucinas são capazes de aprimorar a comunicação intercelular, evidências tem indicado a transferência significativa de informações intercelulares via liberação extracelular de microvesículas e exossomos, coletivamente chamadas vesículas extracelulares (VEs). Vesículas extracelulares são populações heterogêneas de nano a micro vesículas, de ocorrência natural, liberada essencialmente por todos os tipos celulares. VEs são formadas por uma bicamada lipídica com tamanho que pode variar entre 30 e $10.000 \mathrm{~nm}$ de diâmetro (WILLMS et al., 2018). Recentemente, elas tem emergido como um importante componente de comunicação intercelular, principalmente pela habilidade de transferir conteúdo biológico (proteínas, lipídios, ácidos nucleicos) de uma célula para outra. Tal capacidade possibilita a regulação de diversos processos celulares: reparo tecidual (GATTI et al., 2011), manutenção do fenótipo tronco (RATAJCZAK et al., 2006), dentre outros.

Essas vesículas são propostas como sendo mini-mapas especializados feitos sob medida sobre a origem das células, além de poderem ser transportadas na corrente sanguínea e nos fluidos corporais. Essas VEs são definidas e classificadas de acordo com tamanho e na origem celular. De acordo com o tamanho, as vesículas podem ser denominadas: exossomos ( $\sim 30 \mathrm{~nm}-120 \mathrm{~nm}$, originada no corpo multivesicular do sistema endossômico) ou microvesículas (>120nm-1000nm, originadas do brotamento direto da membrana celular). De acordo com a origem celular, elas podem ser classificadas em: ectossomo (grande vesícula de membrana), micropartículas, oncossomos (de origem tumoral), protassomos (de origem do tecido da próstata), dentre outras classificações mais específicas (NAMEE; O’DRISCOLL, 2018).

A habilidade das VEs de transmitir seu conteúdo de uma célula doadora para uma célula receptora, parece ser sua característica mais interessante com potencial de ser utilizado em diversas aplicações, como biomarcador ou carreador de fármacos, por exemplo (WILLMS et al., 2018). No tecido tumoral, as VEs possuem importante papel no microambiente, podendo migrar para lugares distantes do tumor primário para facilitar metástases subsequentes. Nesse contexto, as VEs contribuem de diversas formas para a progressão tumoral: na transferência de informações oncogênicas (ANTONYAK et al., 
2011), na modulação imune (CHALMIN et al., 2010) e, principalmente na formação do nicho pré-metastático (COSTA-SILVA et al., 2015).

Além das contribuições celulares, várias propriedades extracelulares favorecem a progressão do tumor, incluindo alta pressão do fluido intersticial, alterações em componentes específicos da MEC e baixa tensão de oxigênio (LEWIS; MURDOCH, 2005; QUAIL; JOYCE, 2013).

\subsubsection{O papel da deficiência de oxigênio para o microambiente tumoral}

Em 1955, a partir dos estudos de Thomlinson e Gray, foi sugerido que as células tumorais eram expostas a um gradiente de oxigênio $\left(\mathrm{O}_{2}\right)$, em que a oxigenação eficiente próximo ao estroma é gradativamente diminuída a medida que se aproxima a regiões centrais do tumor, causando necrose devido anóxia (THOMLINSON, 1965). Essa variação na concentração de $\mathrm{O}_{2}$ desde então tem se mostrado como importante fator na transformação celular. De forma geral, a hipóxia contribui para alteração de diversos processos celulares: mutagênese, carcinogênese, resistência a apoptose, aumento da motilidade celular, metástase, angiogênese e resistência a múltiplas drogas, contribuindo de forma significativa para a progressão tumoral (BERTOUT; PATEL; SIMON, 2008).

O oxigênio molecular é um nutriente essencial que serve como substrato chave para a produção de ATP e inúmeras reações bioquímicas intracelulares. Sendo assim, a manutenção da homeostase de oxigênio é essencial para sobrevivência (NAKAZAWA; KEITH; SIMON, 2016b). O ar ambiente possui aproximadamente $21 \%$ de oxigênio (150 $\mathrm{mm} \mathrm{Hg}$ ), enquanto que nos tecidos mamários normais existe o suprimento de $2 \%$ a $9 \%$ de $\mathrm{O}_{2}$ (BERTOUT; PATEL; SIMON, 2008).

A pressão parcial de oxigênio é um fator do microambiente que possui importante papel na progressão tumoral e nas respostas ao tratamento. A entrega limitada de oxigênio ocorre em tumores sem vascularização ou com microcirculação deficiente (DEWHIRST et al., 1989; LI; O’DONOGHUE, 2008). Pode-se considerar dois tipos de hipóxia tumoral: intermitente ou crônica. Na hipóxia crônica, o tecido é caracterizado pela presença da hipóxia prolongada devido o crescimento tumoral ocorrer longe de vasos sanguíneos. Por outro lado, a hipóxia intermitente resulta de mudanças transitórias na tensão de oxigênio, devido a obstrução temporária do fluxo sanguíneo (BROWN; GIACCIA, 1998). 
Concentrações de oxigênio podem influenciar diretamente a diferenciação e a auto-renovação celular. Uma das hipóteses existentes acreditam que células tronco se beneficiam de nichos hipóxicos onde o dano oxidativo ao DNA pode ser reduzido (KEITH; SIMON, 2007). Células tronco quiescentes da medula óssea sobrevivem em um ambiente hipóxico (aproximadamente 1-2\% de $\mathrm{O}_{2}$ ) no tecido hematopoietico (CIPOLLESCHI; SBARBA; OLIVOTTO, 1993). Desde então, algumas evidências apontam que o cultivo celular em hipóxia conferem um fenótipo imaturo as células tumorais (AXELSON et al., 2005).

A exposição das células tumorais à hipóxia dá início a ativação de diversas vias de sinalização intracelular que podem em seguida promover diversos processos celulares que contribuem para a progressão tumoral. Dentre estas vias destaca-se: via de fator induzido por hipóxia (HIF - hypoxia inducible factor), via do complexo mTOR, via da autofagia, respostas ao estresse do retículo endoplasmático, dentre outras (NAKAZAWA; KEITH; SIMON, 2016b).

O HIF é membro da família bHLH-PAS que se liga a sequências canônicas de DNA (elementos reguladores de hipóxia - HRE). Ela consiste em duas subunidades, alfa e beta, e ativa a expressão de pelo menos 150 genes relacionados a regulação do metabolismo, sobrevivência, motilidade, integridade de membrana basal, angiogênese, hematopoiese, dentre outras funções (WANG et al., 1995; WANG; SEMENZA, 1995). A proteína HIF1 $\alpha$ media múltiplas respostas adaptativas à disponibilidade reduzida de oxigênio, tais como: o aumento na síntese e captação de glicose e glutamina e, redução do catabolismo de piruvato e do consumo de oxigênio pela mitocôndria (NAKAZAWA; KEITH; SIMON, 2016b).

Em resposta ao aumento na atividade glicolítica, a supressão na produção de espécies reativas de oxigênio (ERO) pela cadeia transportadora de elétrons (CTE), parece ser fundamental para função da proteína HIF. A subunidade $1 \alpha$ de HIF induz a expressão de piruvato desidrogenase 1 (PDK1), cuja fosforilação inibe a piruvato desidrogenase mitocondrial (PDH). A PDH converte o piruvato glicolítico em NADH e acetil-coA na mitocôndria promovendo o metabolismo mitocondrial oxidativo (NAKAZAWA; KEITH; SIMON, 2016b). Tal alteração metabólica pode ser usada por células de tumores mamários para colonizar o fígado, ossos e pulmões, por ser um processo que colabora com a metástase (DUPUY et al., 2015). 
HIF1 $\alpha$ também regula diretamente a expressão da enzima lactato desidrogenase A (LDHA), que é responsável pela conversão do piruvato glicolítico em lactato, além da regulação do transportador monocarboxilato 4 (MCT4), que pela sua interação com a superfície celular media o efluxo de lactato (DOHERTY et al., 2013). Adicionalmente, HIF1 $\alpha$ altera indiretamente o metabolismo mitocondrial. Dentre outras induções, HIF1 $\alpha$ inibe a biogênese mitocondrial via MYC reduzindo o número de mitocôndrias pela expressão de BNIP3 que é responsável por promover a mitofagia (SEMENZA, 2013). Tal processo pode acontecer decorrente de um ajuste no número de mitocôndrias para atender exigências metabólicas ou durante estágios específicos de desenvolvimento celular (LU et al., 2013).

\subsubsection{O papel da privação de glicose para o microambiente tumoral}

Tradicionalmente, as células neoplásicas que compõem os tumores eram retratadas como populações homogêneas de células até que a hiperproliferação combinada ao aumento gradativo da instabilidade genética levou ao aparecimento de distintas subpopulações. Estas refletem uma heterogeneidade clonal com visível diversidade histopatológica, com regiões marcadas com vários graus de diferenciação, proliferação, vascularização, inflamação e invasão (HANAHAN; WEINBERG, 2011).

Nos organismos multicelulares o ambiente normalmente se apresenta com abundância de nutrientes. Para prevenção de problemas de proliferação celular exacerbada, as células são estimuladas a captar nutrientes do ambiente apenas após a estimulação por fatores de crescimento (MATTHEW G. VANDER HEIDEN, LEWIS C. CANTLEY, 2010). Na presença de oxigênio, células diferenciadas metabolizam glicose pela via oxidativa, transformando-a em dióxido de carbono e água. Essa reação produz NADH que abastece a cadeia fosforilativa para maximizar a produção de ATP pela mínima produção de lactato.

Células neoplásicas, no entanto, devido a mudanças no metabolismo energético, passam por uma reprogramação metabólica (HANAHAN; WEINBERG, 2011). Dessa forma, as células tumorais tornam-se capazes de escapar dos mecanismos de regulação do crescimento, resultando em uma captação descontrolada de nutrientes, particularmente glicose, de forma a contribuir com o crescimento e a proliferação celular, mesmo que isso exceda as demandas energéticas e de oxigênio (MATTHEW G. VANDER HEIDEN, LEWIS C. CANTLEY, 2010). 
O conceito que envolve a transformação oncogênica para o desenvolvimento de células neoplásicas a partir de uma célula precursora normal envolve sobretudo a capacidade adquirida dessas células de serem genética e metabolicamente transformadas para se desenvolverem mesmo em ambientes hostis (COSTELLO; FRANKLIN, 2012). A ativação aberrante de oncogenes e/ou perda de supressores tumorais possibilita que as células neoplásicas absorvam toda a glicose disponível de forma constitutiva, ou seja, consumindo nutrientes constantemente mesmo na ausência de estímulos, de forma a sustentar a proliferação descontrolada (PAVLOVA; THOMPSON, 2016). Sendo assim, células mutantes que adquirem vantagem nutricional sobre as células não-mutantes vizinhas, fazem com que as primeiras sejam capazes de crescer em detrimento da última. Tal propriedade contribui para competição célula-célula, levando ao aparecimento de células cada vez mais agressivas (PAVLOVA; THOMPSON, 2016).

As observações de Otto Warburg em 1924 contribuíram para que se pudesse compreender que as células tumorais metabolizam a glicose de forma distinta das células normais (OTTO WARBURG; WIND; NEGELEIN, 1923). De acordo com Warburg, as demandas energéticas necessárias para a proliferação de células tumorais ocorrem pelo completo catabolismo da glicose tanto pelo processo de glicólise aeróbica quanto pela fosforilação oxidativa mitocondrial, de forma a maximizar a produção de ATP (MATTHEW G. VANDER HEIDEN, LEWIS C. CANTLEY, 2010).

Portanto, as alterações metabólicas influenciam a tumorigênese da seguinte forma: (1) afetando o influxo de metabólitos e conferindo um consequente aumento na habilidade de adquirir os nutrientes necessários; (2) moldando a maneira como os nutrientes são preferencialmente atribuídos a vias metabólicas; (3) exercendo efeitos de longa duração sobre a proliferação e diferenciação celular (PAVLOVA; THOMPSON, 2016). Todas essas alterações são decorrentes do estímulo ambiental de deficiência de nutrientes.

As alterações metabólicas coordenadas em células tumorais se estendem além da simples síntese de ATP. Apesar da hidrólise de ATP em ADP ser essencial para liberação de energia necessária as demais reações bioquímicas, nem toda glicose pode ser utilizada para produção de ATP, pois vários intermediários metabólicos são necessários para a síntese de macromoléculas (MATTHEW G. VANDER HEIDEN, LEWIS C. CANTLEY, 2010). 


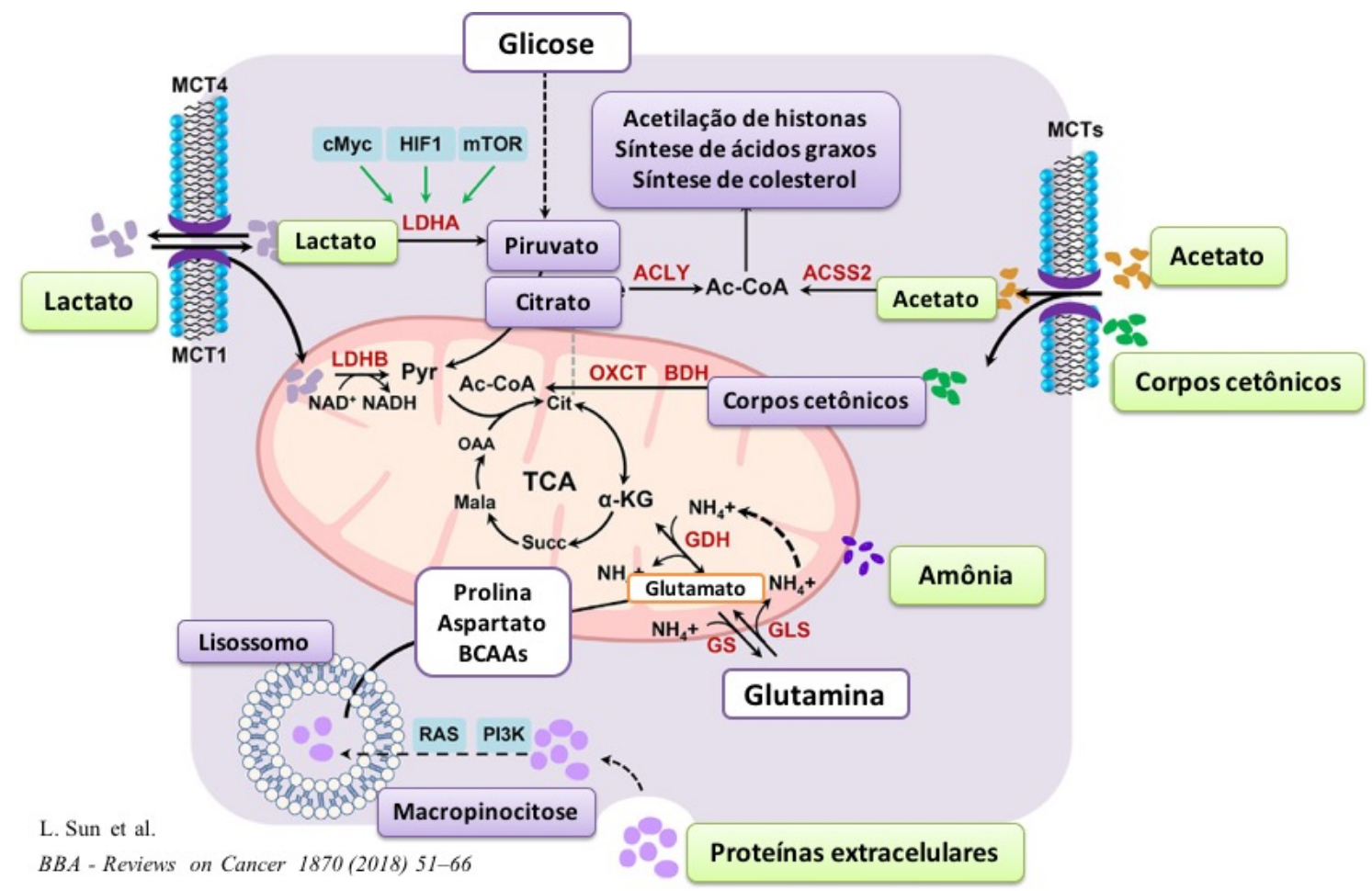

Figura 7 - Vias metabólicas e sintéticas principais na célula tumoral - produtos metabólicos: lactato, acetato, corpos cetônicos, amônia, proteínas exógenas. O lactato gerado pela enzima LDHA (lactato desidrogenase) pode ser exportado para o meio extracelular pelo transportador MCT4 (monocarboxilato 4), enquanto que o lactato exógeno pode ser importado pelo transportador MCT1 (monocarboxilato 1); o acetato intracelular é metabolizado pela ACSS2 a Acetil-coA que é responsável pela acetilação das histonas, além da síntese de colesterol e ácidos graxos. Aumento nos níveis de glutamato facilita a síntese de prolina, aspartato e BCAAs; proteínas extracelulares podem ser absorvidas, digeridas ou decompostas em aminoácidos pelos lisossomos, através do processo de macropinocitose, sob a supervisão de RAS, PI3K. Siglas: HIF: hypoxia inducible fator, mTOR: mammaliam target of rapamysin, PI3K: phosphatidylinositol 3-kinase, LDHA: lactate dehydrogenase A, LDHB: lactate dehydrogenase B, MCT: monocarboxylate transporter, ACLY: ATP citrate lyase, ACSS2: acetyl-coA synthetase 2, BDH: D- $\beta$ OHB dehydrogenase, OXCT: succinyl-CoA:3-oxoacid-CoA transferase, GLS: glutaminase, GDH: glutamate dehydrogenase, GS: glutamine synthetase, Ac-CoA: Acetyl-coenzimeA, $\alpha-\mathrm{KG}$ : $\alpha$-ketoglutarate, Succ: succinate, Mala: malate, OAA: oxaloacetic acid, BCAAs: branched-chain amino acids Adaptado de: SUN et al., 2018.

Existe uma heterogeneidade de escolha do tipo de via metabólica a ser utilizada pela célula tumoral. Dependendo da disponibilidade de nutrientes, algumas células preferencialmente metabolizam pela via glicolítica, enquanto outras pela via oxidativa. Tal heterogeneidade metabólica permite a colaboração entre células adjacentes, contribuindo para a proliferação das mesmas e o consequente crescimento do tumor (MARTINEZ-OUTSCHOORN et al., 2017). Por exemplo, o lactato e o piruvato gerados pela glicólise podem ser transferidos para o meio extracelular, captados e utilizados pelas células adjacentes como substrato para reações anabólicas de geração de ácidos graxos, corpos cetônicos, esteroides e acetilação de proteínas (DOHERTY et al., 2013). Portanto, tumores não são metabolicamente homogêneos e as células tumorais que o compõe podem utilizar catabólitos diversos. 
Glicose e glutamina servem como nutrientes primários para completa proliferação celular, portanto seu consumo excede o dos outros nutrientes, inclusive no metabolismo de linhagens de câncer de mama (EL ANSARI et al., 2018). A glutamina, apesar de não ser o alvo central desse estudo, possui importante papel na síntese proteica em células tumorais devido a sua fonte de carbono e nitrogênio, de forma que, recentemente, tem havido um interesse crescente no entendimento da importância da glutamina e outros nutrientes essenciais para o crosstalk entre crescimento celular, proliferação e sobrevivência por evasão de morte (GWANGWA; JOUBERT; VISAGIE, 2019) que implicam diretamente no sucesso terapêutico. Células variantes presentes em linhagem de câncer de mama agressivo, após sobreviver ao ambiente na ausência de glutamina faz com que a pressão ambiental favoreça o aparecimento de células mais tumorigênicas e metastáticas que as parentais (SINGH et al., 2012).

Ajustes metabólicos tumorais visam fornecer colaborativamente, pelo relacionamento intercelular, intermediários metabólicos (carbono, nitrogênio e energia livre) para a síntese de novas macromoléculas necessárias para o crescimento e proliferação celular (MATTHEW G. VANDER HEIDEN, LEWIS C. CANTLEY, 2010). Tal mecanismo foi observado tanto entre células tumorais entre si quanto na interação célula tumoral e estroma.

Transportadores de monocarboxilato (MCT) são necessários para a liberação de captação desses catabólitos. Dentre estes, o lactato é incorporado pelas células através dos transportadores carboxilatos (MCT1 ou MCT4) e utilizado para a produção de energia através do metabolismo oxidativo (PILLAI et al., 2019). Tal lactato incorporado dará origem ao glutamato e/ou a alanina (KENNEDY et al., 2013). A regulação dos transportadores monocarboxilatos é realizada por fatores de transcrição tais como HIF e NFkB, e de forma interessante, são fatores altamente expressos em fibroblastos associados ao câncer, conferindo vantagens na progressão tumoral (WILDE et al., 2017).

Em adição as influências autócrinas e parácrinas das células que compõem o estroma, os fibroblastos associados ao câncer (FAC) também atuam sobre as células tumorais fazendo translocações de substratos metabólicos por meio de exossomos. Zhao e colaboradores demonstraram que exossomos de FAC contendo lactato, acetato, amino ácidos, lipídios e outros intermediários do ciclo ATC são capazes de reprogramar células tumorais para inibir a fosforilação oxidativa e promover a glicólise via miRNA e transferência de substratos (ZHAO et al., 2016). 
Outro mecanismo de sobrevivência desenvolvido pelas células tumorais em resposta a longos períodos de privação de nutrientes é o processo de macroautofagia (NAKAZAWA; KEITH; SIMON, 2016b). Durante a macroautofagia as macromoléculas e organelas intracelulares são envolvidas em estruturas membranosas e se fundem com lisossomos. Uma vez dentro dos lisossomos, a mesma é degradada por proteases e lipases. Tais nutrientes liberados permitem a viabilidade celular por longos períodos. Nesse contexto, a autofagia pode promover um mecanismo temporário de sobrevivência, que retarda a apoptose e dá as células a chance de sobreviver (FUNG et al., 2008). A indução é dirigida pela ativação de proteínas sensores de estresse metabólico tais como a 5'AMPproteína quinase ativada (AMPK) (JUNG et al., 2010)121.

Considerando que a deficiência de nutrientes induz autofagia, o AMPK é um importante ativador da mesma. Sua síntese pode ser estimulada pela privação de glicose e consequente diminuição nos níveis de ATP. O AMPK colabora com a manutenção de energia por agir sobre processos catabólicos para ativação de vias de suprimento energético, sendo assim, o AMPK é considerado um sensor de energia celular. Portanto, células cultivadas sob baixas concentrações de glicose apresentam alta atividade de AMPK (MORUNO; PÉREZ-JIMÉNEZ; KNECHT, 2012).

A expressão de genes e proteínas relacionadas a autofagia está consideravelmente aumentada em câncer de mama mais agressivos. LC3 (cadeia leve 3 da proteína associada a microtubo) é uma proteína de membrana de autofagossomo, utilizada como marcador de autofagia. Suas isoformas LC3A, LC3B e LC3C possui diferentes perfis de expressão teciduais, tanto no tecido sadio quanto doente. No câncer de mama triplo-negativo, a expressão aumentada de LC3B é considerada um marcador de mau prognóstico, podendo indicar que a autofagia é um processo crucial para conferir vantagens proliferativas e invasivas que são características nesse tipo de tumor (LEFORT et al., 2014).

A morfologia e a regulação da autofagia tem sido investigada durante os processos de privação de glicose em câncer por se tratar de um mecanismo de sobrevivência celular (KABEYA et al., 2000). A autofagia é uma via de degradação intracelular responsável por prover nutrientes sob condições limitadas de energia (autofagia não seletiva), além de funcionar como um controle de qualidade de proteínas e/ou organelas em mau funcionamento (autofagia seletiva). Um dos processos autofágicos seletivos que podem ser realizados é a mitofagia. Tal processo pode acontecer decorrente de um ajuste no número de mitocôndrias para atender exigências metabólicas ou durante estágios específicos de desenvolvimento celular (LU et al., 2013). 


\subsection{Mitocôndria e a dinâmica mitocondrial}

Uma função essencial da mitocôndria em células de mamíferos é fornecer ATP através da fosforilação oxidativa. Adicionalmente, a mitocôndria integra várias vias metabólicas e, através desse processo, sintetiza intermediários necessários na síntese de biomassa celular. Além disso, a mitocôndria exerce funções especializadas de manutenção da homeostase de $\mathrm{Ca}^{2+}$ e regulação da apoptose. Essas organelas também produzem espécies reativas de oxigênio como metabólito secundário da via oxidativa, agindo como molécula sinalizadora no meio fisiológico, ou podendo causar toxicidade quando em excesso (BURKE, 2017; SRINIVASAN et al., 2017).

Mitocôndrias saudáveis são dinâmicas de forma a facilitar mudanças na eficiência funcional da mesma. A morfologia mitocondrial é resultado da interação entre eventos rápidos de fusão e fissão (HOPPINS; LACKNER; NUNNARI, 2007). Ciclos de fissão e fusão asseguram a morfologia, número e funcionamento bioenergético (KNOTT et al., 2008). A fusão mitocondrial ocorre por um processo de duas etapas de fusão das membranas mitocondriais. Primeiramente, ocorre a junção das membranas mitocondriais externas, em seguida, ocorre a fusão da membrana mitocondrial interna. A fusão da membrana externa é mediada pelas proteínas mitofusinas MFN1 e MFN2 (LEGROS et al., 2002), enquanto que a fusão da membrana interna é mediada pela proteína OPA1 (HOPPINS; LACKNER; NUNNARI, 2007; LEGROS et al., 2002).

A fissão mitocondrial, por outro lado, é mediada pela GTPase DRP1 (SMIRNOVA et al., 2001). As propriedades funcionais do DRP1 são moduladas por inúmeras modificações pós-translacionais, incluindo fosforilação, SUMOilação, ubiquitinação e S-nitrosilação. A proteína DRP1 é fosforilada em dois sítios: serina 616 e serina 637. A fosforilação na serina 616, pela quinase dependente de ciclina 1 (Cdk-1), e a desfosforilação de serina 637, pela calcineurina, promovem a fissão mitocondrial (GAWLOWSKI et al., 2012).

O DRP1 é recrutado para a membrana externa mitocondrial pelas proteínas de ancoragem (Fator de fissão de mitocôndria (Mff - mitochondrial fission factor) e proteína de fissão mitocondrial (Fis1 - mitochondrial fission 1protein), com as quais forma-se um anel contrátil ao redor da membrana externa e interna, que ao se comprimir causa a fragmentação mitocondrial (GANDRE-BABBE; VAN DER BLIEK, 2008; JAMES et al., 2003). A fusão da mitocôndria resulta em vantagens celulares sob alta demanda 
energética. Portanto, a dinâmica mitocondrial tem um caráter fisiológico, sendo assim, a disfunção mitocondrial induz alterações nessa dinâmica que podem contribuir para modular a integridade e funções mitocondriais, exacerbando os efeitos danosos e promovendo, entre outras doenças, a oncogênese (SRINIVASAN et al., 2017).

Doenças e condições ambientais adversas causam diversos danos funcionais na mitocôndria: mutação no DNA mitocondrial, deleções, prejuízo na replicação do DNA (WALLACE, 2015). Estresse resultante da condições ambientais, tais com a de hipóxia, por exemplo, afeta a morfologia mitocondrial. Mitocôndrias normalmente apresentam-se concentradas na região periférica do envelope nuclear, enquanto que células que sofreram danos mitocondriais, apresentam mitocôndrias em menor número e tamanho, fragmentadas e distribuídas ao longo de todo o citoplasma, além de possuir crista mitocondrial desorganizada (SRINIVASAN et al., 2017). No câncer, tais alterações podem comprometer diretamente o tratamento antitumoral. Anormalidades no DNA mitocondrial afeta a resposta e o resultado clínico do tratamento, sendo a mitocôndria considerada atualmente um importante alvo terapêutico (VAN GISBERGEN et al., 2015).

Alterações na função mitocondrial tem importante influência na iniciação, progressão e metástase tumoral de forma a ser considerada um hallmark do câncer. No câncer de mama não é diferente. Alguns reguladores intracelulares para metástase, particularmente os relacionados ao rearranjo do citoesqueleto para aumentar a motilidade, exigem um aumento de ATP. Considerando tal exigência energética, as mitocôndrias formam uma estrutura tubular para interligar-se com outras organelas. Sendo assim, a medida que as exigências energéticas mudam, a mitocôndria cliva DRP-1 para poder reposicioná-lo nos lugares da célula que mais precisam, principalmente durante os processos de migração e invasão (ZHAO et al., 2013). Dessa forma, a dinâmica mitocondrial contribui para os eventos iniciais da metástase no câncer de mama, podendo ser um fator a ser avaliado para a sua prevenção.

O microambiente contribui significativamente na mudança da dinâmica mitocondrial. O aumento na expressão de DRP-1 e a estimulação da fissão mitocondrial pode ser desencadeada pela hipóxia em linhagem de câncer de mama metastático MDAMB-231, mas não em linhagem não metastática MCF7 (HAN et al., 2015). Esses resultados indicam o papel do DRP-1 na dinâmica mitocondrial induzida pela hipóxia que promove a migração e a resistência a quimioterápicos em células de câncer de mama. 
A mitocôndria também possui importante papel na pluripotência celular. Nas condições de autorrenovação, caracterizada pela alta expressão de genes de pluripotência (NANOG, OCT4, SOX2), a dinâmica mitocondrial e a manutenção de funções próprias da mitocôndria são cruciais para a manutenção da pluripotência (TODD et al., 2010). Redução no conteúdo do DNA mitocondrial induz reprogramação celular para o processo de transição epitélio-mesenquimal em células epiteliais de mama, enquanto que em células tumorais, alteração na mitocôndria contribuem para o aumento no potencial tumorigênico e o aparecimento de fenótipo tronco (GUHA et al., 2014).

Essa dinâmica mitocondrial depende do equilíbrio necessário para a célula tumoral proliferar. Nesse contexto, células do câncer precisam equilibrar a necessidade bioenergética e biossintética para crescer, proliferar e sobreviver mesmo em condições adversas. Sendo assim, as células tumorais alteram o fluxo metabólico através das vias mitocondriais (AHN; METALLO, 2015). A mitocôndria participa da integração metabólica de diversas vias: ciclo do ácido tricarboxílico, metabolismo de ácidos graxos, oxidação de aminoácidos, além da fosforilação oxidativa. Devido a defeitos sobre enzimas mitocondriais específicas ou efeitos tais como hipóxia, perda de potencial de membrana ou depleção de DNA mitocondrial causam acúmulo de metabólitos, responsáveis pela sinalização e fenótipo das doenças (SRINIVASAN et al., 2017).

A glicose é o principal nutriente utilizado para a síntese de ATP nas vias metabólicas mitocondriais. Durante a privação de glicose, no entanto, a mitocôndria continua a metabolizar prótons para gerar ATP, o que resulta num processo compensatório para a sobrevivência e escape da morte celular (CUI et al., 2017). Outra consequência da prevalência da via glicolítica em células tumorais é o excesso da geração de lactato. Tal produção permite a incorporação rápida de carbono na biomassa, possibilitando que a célula prolifere mais rapidamente (MATTHEW G. VANDER HEIDEN, LEWIS C. CANTLEY, 2010).

É comprovada a forte correlação entre captação aumentada de glicose com o aumento da acidose (ANEMONE et al., 2019). A acidose é exacerbada pela diminuição na perfusão, assim como o pH diminui a medida que aumenta a distância dos vasos sanguíneos (HELMLINGER et al., 1997). Isso resulta no acúmulo de ácidos no meio extracelular, enquanto que o lactato surge como importante fonte nutritiva para células do estroma tumoral.

A acidose extracelular, uma consequência do metabolismo anaeróbico, pode reprogramar a via metabólica mitocondrial para preservar a produção eficiente de ATP. 
Acidose inicia um programa rápido e reversível para homeostase que reestrutura as mitocôndrias pela regulação da sua dinâmica (DRP1, MFN), assim como para manter a arquitetura das cristas, para reconfigurar a eficiência mitocondrial e manter sua função, colaborando com a sobrevivência celular (KHACHO et al., 2014).

\subsubsection{O papel da acidose para o microambiente tumoral}

Sumariamente, o aumento na distância necessária para difusão de oxigênio do capilar sanguíneo para as regiões mais internas dos tumores sólidos cria um estado hipóxico regional. Tal hipóxia cria uma barreira proliferativa na produção de ATP pela via oxidativa. Para tanto, as células tumorais passam por uma reprogramação metabólica, passando a metabolizar glicose pela glicólise anaeróbica. Tal mudança metabólica promove a transformação de glicose em ácido lático, sendo responsável pelo significativo aumento da acidez extracelular (OTTO WARBURG; WIND; NEGELEIN, 1923; PEPPICELLI et al., 2017a).

A acidose regional produz uma nova barreira ao crescimento celular, se tornando um novo fator para uma pressão seletiva ambiental. As adaptações à toxicidade mediada pelo $\mathrm{pH}$ ácido confere vantagens significativas a determinada população celular em detrimento de outra. Associado a isso, células adaptadas ao $\mathrm{pH}$ ácido adquirem propriedades migratórias e invasivas, promovendo invasão através do tecido normal adjacente (GATENBY; GILLIES, 2008).

As células tumorais passam por significativas adaptações para crescer no meio ácido. A nível genômico, acidose pode induzir instabilidade genômica através de quebras cromossômicas levando a evoluções somáticas (MORITA et al., 1992). O microambiente ácido provoca uma importante pressão seletiva que contribui para o surgimento de clones mais agressivos e resistentes.

Umas das adaptações celulares causadas pela acidose é o aumento na produção de lisossomos e redistribuição dos mesmos na membrana perinuclear, onde eles podem fundir e liberar seu conteúdo (proteases de $\mathrm{H}^{+}$) para o microambiente ao redor. Essa adaptação contribui para o remodelamento da matriz extracelular e invasão local (ROTHBERG et al., 2013; ROZHIN et al., 1994) além de já se saber que é um fator que contribui para a autofagia crônica (WOJTKOWIAK et al., 2012). Apesar da importância ainda não ser clara, a adaptação ao ambiente ácido também está associada ao aumento na liberação de vesículas extracelulares como mediadores na comunicação célula-célula por 
carrear informações (PAROLINI et al., 2009). Adicionalmente, sabe-se que a acidificação estimula a produção de citocinas inflamatórias pelo estroma ou endotélio adjacentes (DONG et al., 2013).

\subsubsection{Célula tronco tumoral}

Alguns conceitos são necessários para se entender o fenótipo das células tronco tumorais (CTT). Existem algumas populações celulares com características específicas, que ajudaram na atual compreensão do que é a população de CTT. Dentre estas destacamse as: células tronco embrionárias, células tronco pluripotentes, células tronco totipotentes e, por fim células tronco tumorais. Para entender o papel de cada uma, abaixo se seguirão alguns conceitos.

Denomina-se célula tronco embrionária uma massa de células da pré-implantação embrionária que pode se propagar indefinidamente, assim como se diferenciar em células de todos os três folhetos germinativos (endoderme, mesoderme e ectoderme) (WOBUS; BOHELER, 2005). De forma semelhante, as células tronco pluripotentes, tem sua definição baseada em duas propriedades: autorrenovação e potência. A autorrenovação é a capacidade de se dividir indefinidamente, produzindo células-filhas inalteradas que mantém as mesmas propriedades das células progenitoras. No entanto, através de estímulos particulares, tais células saem do programa de autorrenovação e adquirem o potencial de se diferenciarem em células especializadas (ROMITO; COBELLIS, 2016).

De forma complementar, células totipotentes são aquelas originadas nas primeiras divisões celulares após a fertilização durante o desenvolvimento embrionário. Elas são capazes de se diferenciar em qualquer tipo celular, células embrionárias ou extraembrionárias, colaborando para os diversos estágios do desenvolvimento do embrião (CHENG; YAO; REID, 2008). De forma não muito diferente, conceitua-se célula tronco tumoral aquela população celular proveniente do tumor que possui capacidade de autorrenovação, diferenciação e tumorigenicidade (YUA et al., 2012), ambas propriedades semelhantes ao fenótipo tronco, exceto a capacidade tumorigênica.

Dois modelos foram propostos para o surgimento do fenótipo tronco tumoral: o modelo evolutivo clonal e o modelo de célula tronco (Fig. 8) (VISVADER, 2011). De acordo com o modelo evolutivo clonal, também denominado de modelo não-hierárquico, todas as células tumorais possuem a mesma capacidade de propagação. Nesse modelo, a heterogeneidade resulta de clones intra-tumorais que se desenvolvem através de mutações 
sequenciais. No modelo de célula tronco tumoral (CTT), por outro lado, acredita-se que apenas uma fração de células residentes no tumor possuem a capacidade de propagação. Esta CTT pode ser proveniente de uma célula tronco normal alterada, ou de uma célula tumoral que se reprogramou para adquirir o fenótipo tronco (YUA et al., 2012). Pode-se assim dizer que as CTTs podem ser originadas de uma célula progenitora restrita ou de uma célula diferenciada (VISVADER, 2011).

Modelo de evolução clonal

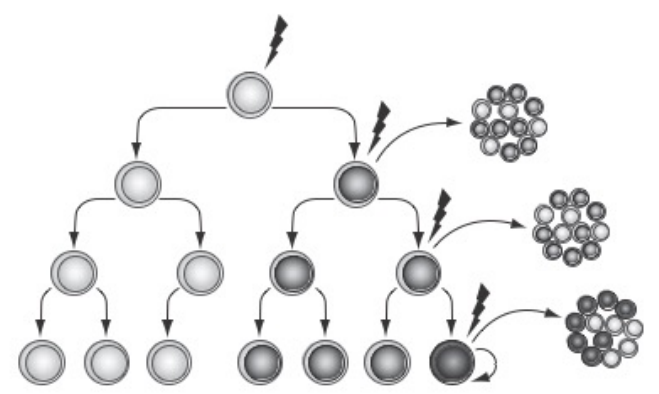

Modelo não-hierárquico
Modelo de célula tronco

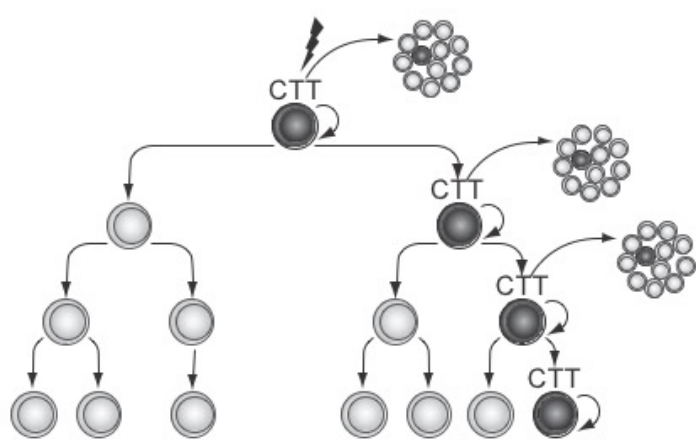

Modelo hierárquico

C 2010 The Authors

Journal Compilation $\mathcal{O}$ Blackwell Publishing Asia Pty Ltd

Figura 8 - Modelos de heterogeneidade e propagação tumoral. De acordo com o modelo de evolução clonal, todas as células possuem a mesma capacidade tumorigênica. Novos clones tumorigênicos podem emergir numa maneira aleatória e contribuir para a heterogeneidade tumoral. No modelo de célula tronco tumoral (CTT) uma população de CTT são capazes de propagar o tumor. Essas células possuem propriedades de auto renovação e são capazes de recapitular a hierarquia tumoral. Adaptado de LINDEMAN; VISVADER, 2010.

Assim como muitos tumores sólidos, acredita-se que o câncer de mama também apresenta uma hierarquia funcional onde uma fração dessas células são caracterizadas como células-tronco tumorais (CTTs). Alterações genômicas permitindo o escape da regulação do ciclo celular, ativação de fatores de crescimento de forma independente e resistência a apoptose constituem características próprias das CTTs. Do mesmo modo tem se demonstrado uma possível relação entre a transição epitélio-mesenquimal com o aparecimento da população de CTTs no câncer de mama (MANI et al., 2008), constituindo assim uma população de células neoplásicas difíceis de atacar/erradicar e quimiorresistentes (REYA et al., 2001; SMALLEY, 2010).

A relação entre TEM e fenótipo tronco, em vários tumores sólidos assim como no câncer de mama, pode ser justificado pelas análises de expressão gênica em célula única que revelaram que os genes epiteliais e mesenquimais podem ser co-expressos na mesma célula (GROSSE-WILDE et al., 2015). A transição epitélio-mesenquimal faz com que as 
células tronco possuam a maior extensão de plasticidade celular, que possibilita a flexibilidade de passagem de um fenótipo celular para outro (MIKKERS; FRISÉN, 2005).

A autorrenovação e diferenciação de células tronco, normais ou tumorais, são reguladas basicamente por três vias de sinalização: Hedgehog, Notch e Wnt/ $\beta$-catenina. A via Wnt dirige a divisão simétrica em células tronco (LE GRAND et al., 2009). Ativação da via Notch, assim como da via Hedgehog, por outro lado, é responsável por contribuir com a expansão e a variabilidade de células tronco e progenitoras (CHIBA, 2006).

A sinalização pela via Notch é atrativa devido ao seu envolvimento em vários processos celulares, tais como proliferação, diferenciação e sobrevivência celular. Além disso, a sinalização por Notch está envolvida no potencial e autorrenovação e tumorigênese. No câncer de mama, Notch pode promover autorrenovação em células tronco da mama, além de proliferação de células progenitoras, conforme demonstrado pelo aumento em 10 vezes na formação de mamoesferas. Pela ação em células tronco e sua consequente capacidade de manter as células em condições proliferativas e indiferenciadas, a sinalização por Notch tem importante papel no desenvolvimento de tumores de mama (BRENNAN; BROWN, 2003; DONTU et al., 2004).

Células tronco são caracterizadas molecularmente por expressar marcadores de pluripotência, tais como: Oct4, Sox2, Nanog, Lin28, Klf4, Notch1 e c-myc. A coexpressão desses marcadores pode reprogramar células somáticas em células tronco embrionárias, sugerindo que a expressão combinada de marcadores de pluripotência com oncogenes, pode induzir o estado indiferenciado nessas células (KONG et al., 2011; TAKAHASHI et al., 2007; YU et al., 2007). Por causa da função da expressão de Oct4, Sox2 e Nanog na progressão do câncer de mama, medidas terapêuticas para atingir esses alvos são essenciais (APOSTOLOU; TOLOUDI; PAPASOTIRIOU, 2015).

Várias evidências sugerem a expressão de Oct4, Nanog e Sox2 (Sex-determining region $y(S R Y)$-Box2) está associada com população de CTT, inclusive no câncer de mama. O fator de transcrição Oct4, transcrito pelo gene POU5F1, é um dos reguladores da pluripotência (DE JONG; LOOIJENGA, 2006). O Oct4 é expresso especificamente em células pluripotentes, e sua expressão é suficiente para induzir pluripotência em células somáticas (STERNECKERT; HÖING; SCHÖLER, 2012; TAKAHASHI et al., 2007). Fatores de transcrição responsáveis por reprogramação celular, tais como Oct4, 
são altamente expressos em subpopulações de células tronco tumorais indiferenciadas, sendo empregados na manutenção do fenótipo tronco.

O aumento na expressão do gene ou proteína transmembrana Oct4 pode induzir a indiferenciação de células de diversos tipos de câncer (KUMAR et al., 2012; MURAKAMI et al., 2015). Tais células perdem a expressão de marcadores de diferenciação e adquirem a habilidade de formar esferoides tumorais, serem resistentes a quimioterapia padrão e a danos por hipóxia, além de poderem aumentar a tumorigenicidade in vivo.

Tem-se descrito que a reprogramação celular se utilizando Oct4 e Sox2 tem importante papel na manutenção do fenótipo tronco em células tronco tumorais. O Sox2, além da sua função de manutenção das propriedades de célula tronco e restrição da diferenciação, é também, assim como Oct4, um dos fatores capazes de reprogramar uma célula humana somática em célula tronco pluripotente (YU et al., 2007). Sendo assim, Sox2 e Oct4 juntos são suficientes para gerar células pluripotentes com características de célula tronco embrionária. A programação de stemness tem importante papel no câncer pois o potencial de autorrenovação favorece que essa mesma célula seja capaz de dar origem a um novo tumor, podendo ser também denominada de célula tumoral iniciadora (HERREROS-VILLANUEVA et al., 2013).

A influência dos marcadores de fenótipo tronco não se restringe a favorecer a célula tumoral. A expressão de Sox 2 em células do câncer de mama é capaz de promover o recrutamento de macrófagos M2 provenientes do microambiente tumoral. Tal influência tem importante papel na liberação de interleucinas e na ativação de vias responsáveis por induzir metástase e contribuir para a progressão tumoral (MOU et al., 2015). De forma semelhante, a interação de células tumorais com fibroblastos associados ao tumor aumenta o perfil de célula tronco tumoral contribuindo para metástase óssea (KUO et al., 2018). Mais uma vez entende-se que a progressão tumoral é multifatorial, sendo intensamente influenciada pelo microambiente.

Outro fator de transcrição importante é o Nanog. A superexpressão de Nanog na glândula mamária não é suficiente para induzir tumor mamário. No entanto, quando Nanog está expresso concomitantemente com Wnt-1 há a promoção de tumorigênese e metástase. De forma que Nanog é capaz de promover a migração e invasão em câncer de mama, levando a uma correlação direta entre a expressão de Nanog e o mau prognóstico em pacientes com tumores de mama (LU et al., 2014). 
As características fenotípicas fornecidas pelo aumento na expressão de indutores de fenótipo tronco implicam na recidiva e quimiorresistência, em especial em tumores de mama (PIVA et al., 2014). A reversão desses efeitos pode ser realizada, por exemplo, silenciando fatores de transcrição indutores de fenótipo tronco, que colabora para o aumento na efetividade de tratamento pela redução da resistência apresentada por células tronco de mama quimiorresistentes (MUKHERJEE et al., 2017).

No câncer de mama, especificamente, o fenótipo tronco é caracterizada pela presença dos seguintes marcadores: CD44, CD133, ALDHA, c-kit, ESA e ABCG2 (ALHAJJ et al., 2003; PRUD'HOMME, 2012). Considerando a heterogeneidade nas isoformas de CD44 expressas por CTT, bem documentada no câncer de mama, é plausível que a regulação de CD44 permite que as CTT mantenham um híbrido entre o fenótipo epitelial e mesenquimal, que está diretamente relacionado ao fenótipo tronco e tumorigenicidade (GROSSE-WILDE et al., 2015; MIKKERS; FRISÉN, 2005; OLSSON et al., 2011).

Para melhor entender as diferenças moleculares entre as células CD24+ e CD44+ nos carcinomas de mama assim como suas células análogas no tecido de mama normal, Shipitsin e colaboradores (2007) realizaram uma análise detalhada do perfil genético específico em cada caso. A análise dos resultados os levaram às seguintes conclusões: (1) o perfil gênico de células tumorais CD44+ é semelhante ao perfil de células tronco; (2) células tumorais e normais CD44+ são mais semelhantes entre si que células CD24+ do mesmo tecido; (3) células tumorais CD44+ e CD24+ estão relacionadas ao mesmo clone de origem; (4) o perfil de expressão gênica distinto entre as células reflete a ativação de vias de sinalização distintas; (5) células com alta expressão de CD44+ possuem um potencial migratório e angiogênico maior; (6) genes envolvidos no metabolismo de carboidratos estão mais expressos em células CD24+; (7) células tumorais de mama CD44+ são ER-negativas mesmo em tumores classificados com ER-positivas; (8) tumores com maioria das células $\mathrm{CD} 44+$ possuem pior prognóstico quando comparado a tumores com maioria celular CD24+. A análise molecular CD24+ e CD44+ em carcinomas mamários revela um perfil de populações celulares definidas que fazem parte do tecido tumoral heterogêneo e valida a população tronco em tumores de mama, tendo relevância clínica e terapêutica (SHIPITSIN et al., 2007).

Sendo assim, CD44, CD24 e ALDH são os principais marcadores utilizados para fenótipo tronco em câncer de mama com distintos níveis de diferenciação. Tumores do tipo basal-like $(76,5 \%)$ contem a maior população de células $\mathrm{CD} 44^{+} / \mathrm{CD} 24^{-/ \mathrm{low}}$, assim 
como as células mesenquimais. Enquanto células luminais apresentam fenótipo CD44/low/CD24+ (RICARDO et al., 2011).

Embora já se tenha muitas informações sobre o papel do microambiente tumoral como um fator essencial que contribui para a expressão do fenótipo tronco, muito ainda é necessário entender sobre o papel específico da hipóxia, privação de glicose e acidose nesse contexto. 


\subsection{OBJETIVOS GERAIS}

\subsubsection{Objetivo geral}

Avaliar a capacidade moduladora da hipóxia, acidez e deficiência de glicose sobre fenótipo tronco de populações de células tumorais de mama humano.

\subsubsection{Objetivos específicos}

- Promover a seleção de células resistentes a condições de hipóxia, acidez e deficiência de glicose, avaliando paralelamente a viabilidade, proliferação e morfologia celulares;

- A partir da seleção de linhagens resistentes aos estresses propostos, avaliar a expressão de genes relacionados ao fenótipo tronco tumoral;

- Avaliar da expressão das proteínas relacionadas aos genes diferencialmente expressos;

- Avaliar a liberação de sinalizadores extracelulares: interleucinas próinflamatórias e/ou vesículas extracelulares nas condições de hipóxia, acidez e deficiência de glicose;

- Avaliar a capacidade funcional das células submetidas a condições de hipóxia, acidez e deficiência de glicose, quanto a habilidade de formar colônias, aderir, migrar, crescer sem adesão a substrato;

- Avaliar a influência do co-cultivo da célula tumoral com fibroblastos não tumorigênicos nas condições de hipóxia, acidez e deficiência de glicose. 


\section{CONCLUSÕES E CONSIDERAÇÕES FINAIS}

\subsection{CONCLUSÕES}

- Exposição de células de tumores de mama metastático apresentam diminuição significativa na viabilidade, proliferação com consequentes mudanças morfológicas especificamente na exposição a privação de glicose e meio ácido (glicose $0,5 \mathrm{~g} / \mathrm{L}$ e no $\mathrm{pH}$ 6,2). Tais resultados sinalizaram para maiores investigações quanto as alterações induzidas pela deficiência de glicose e pelo $\mathrm{pH}$ ácido;

- A exposição das células às condições $0,5 \mathrm{~g} / \mathrm{L}$ glicose, $\mathrm{pH} 6,2$ e $200 \mu \mathrm{M}$ $\mathrm{CoCl}_{2}$ por $72 \mathrm{~h}$ altera significativamente a expressão de genes para fenótipo tronco tumoral tanto na linhagem MDA-MB-231 quanto MCF7, destacando-se o potencial de fenótipo tronco maior na linhagem MDAMB-231 que inclusive levou ao aumento na população CD44 /CD24 na condição de glicose $0,5 \mathrm{~g} / \mathrm{L}$;

- A privação de glicose causa diminuição significativa de LC3B após exposição por $24 \mathrm{~h}$ com glicose $0,5 \mathrm{~g} / \mathrm{L}$, sugerindo inibição da indução de autofagia;

- A privação de glicose não é suficiente para causar mudanças morfológicas e nem funcionais na linhagem MDA-MB-231, no entanto, age como importante indutora do fenótipo tronco tumoral, assim como, causa a diminuição significativa da concentração de IL-8 e o aumento significativo de IL-1 $\beta$, sem alteração de IL-6;

- Em relação a indução de alterações de outros componentes do microambiente tumoral, a condição de $0,5 \mathrm{~g} / \mathrm{L}$ glicose causa diminuição significativa no tamanho do esferoide da linhagem MDA-MB-231. Além disso, os fibroblastos migram significativamente mais na condição de 0,5g/L glicose sugerindo que a MDA-MB-231consegue influenciar a migração de fibroblastos, uma das principais células do microambiente tumoral;

- O contato do fibroblasto não transformado com o meio condicionado pela MDA-MB-231 não ativa marcadores de fibroblastos associados ao câncer por si só, dessa forma o estímulo da interação intercelular parece se 
sobrepor ao estímulo apenas da restrição de glicose. Isso marca a importância da heterogeneidade celular e da interação dos múltiplos componentes do microambiente como fatores determinantes no comportamento celular durante a progressão tumoral;

- Outro fator do microambiente, avaliado nesse trabalho, que contribui significativamente para a progressão tumoral é o $\mathrm{pH}$ ácido. De forma cumulativa, o pH ácido afeta a viabilidade, proliferação, interação célulacélula e induz resistência a droga;

- Os resultados de expressão gênica, níveis de marcadores proteicos e morfologia celular apontam o pH 6,2, na exposição aguda e crônica, como responsáveis pela perda progressiva do contato célula-célula e aumento do número de células isoladas sugerindo uma transição parcial para fenótipo mesenquimal;

- Funcionalmente, o pH 6,2 diminui significativamente a migração da MCF7 em relação ao pH 7,2, tanto na condição aguda quanto crônica, além de células expostas à condição aguda tenderem a aderir significativamente mais que as expostas à condição crônica e ao pH 7,2. Adicionalmente, a acidose causa o aparecimento de colônias significativamente mais irregulares, pelo aparecimento de colônias com células mais espaçadas e distantes do centro da colônia devido a provável TEM;

- No cultivo tridimensional, a acidose induz a formação de esferoides maiores e com formato irregular, possibilitando o aparecimento de células com maior potencial migratório e, estimulando o aumento na expressão de NOTCH1 e NANOG. Já no cultivo MCF7 com fibroblastos tridimensionalmente, o contato com a célula tumoral aumenta o potencial migratório dos fibroblastos no $\mathrm{pH}$ ácido;

- A acidose também contribui com o microambiente tumoral pelo estímulo a liberação de vesícula extracelulares, que causa aumento da comunicação intercelular, sendo a maior população formada por exossomos, que in vivo poderia predispor a formação de nicho pré-metastático. Adicionalmente, a exposição às quantidades iguais de vesículas extracelulares isoladas de MCF7 resultou no aumento 1,5 vezes maior na migração dos fibroblastos; 
- Com o somatório dos resultados, acredita-se que, a MCF7, por possuir um fenótipo epitelial, sofre a influência do microambiente para progredir para o fenótipo mesenquimal. Por outro lado, a MDA-MB-231, que já possui fenótipo mesenquimal, sobre a influência do microambiente, progride potencialmente para o fenótipo tronco tumoral.

\section{CONSIDERAÇÕES FINAIS}

Carcinogênese é resultante de diversos processos finamente orquestrados que, com a colaboração da instabilidade genética e epigenética, leva a sinalizações celulares aberrantes tais como aumento no consumo de glicose, na presença ou ausência de oxigênio, aumento do metabolismo pela via glicolítica, aumento na produção, acúmulo e liberação de ácido e lactato, além de alterações na função mitocondrial, que em conjunto colaboram para a progressão do câncer (SAN-MILLÁN; BROOKS, 2017).

Tratamentos convencionais para o câncer geralmente tem como alvo células tumorais diferenciadas e em constante proliferação, no entanto, um número significativo de pacientes adquirem resistência ao tratamento, resultando em metástase e recorrência da doença. Acredita-se que tal recorrência seja resultado do aumento populacional de células iniciadoras de tumor e/ou células tronco tumorais. Associado a essa população celular específica, existe a contribuição do microambiente tumoral que pode influenciar tanto no processo de transição epitélio-mesenquimal potencialmente invasivo quanto no aumento populacional de células com fenótipo tronco tumoral.

Por fim, acredita-se no potencial individual da hipóxia, acidose e privação de glicose que permite a saída das células da sua estrutura convencional, adquirindo fenótipos para contribuir com a progressão tumoral. No entanto, o câncer é formado por sistema de eventos interdependentes, cujos fatores que estão envolvidos com sua iniciação, desenvolvimento e progressão devem ser avaliados em conjunto, embora seja necessário promover estudos de forma independente (MINA et al., 2017).

O entendimento molecular e das características das células tronco tumorais possibilita a busca por novos medicamentos com alvo específico para a particularidade fenotípica das mesmas, na expectativa de finalmente eliminar o que se acredita ser a raiz do problema. 


\section{REFERÊNCIAS BIBLIOGRÁFICAS}

AHN, C. S.; METALLO, C. M. Mitochondria as biosynthetic factories for cancer proliferation. Cancer and Metabolism, v. 3, n. 1, p. 1-10, 2015.

AL-HAJJ, M. et al. Prospective identification of tumorigenic breast cancer cells. Proceedings of the National Academy of Sciences of the United States of America, v. 100, n. 7, p. 3983-8, 1 abr. 2003.

ANEMONE, A. et al. Imaging tumor acidosis: a survey of the available techniques for mapping in vivo tumor pH. Cancer and Metastasis Reviews, 2019.

ANTONYAK, M. A. et al. Cancer cell-derived microvesicles induce transformation by transferring tissue transglutaminase and fibronectin to recipient cells. Proceedings of the National Academy of Sciences, v. 108, n. 12, p. 4852-4857, 22 mar. 2011.

APOSTOLOU, P. et al. Study of the interaction among Notch pathway receptors, correlation with stemness, as well as their interaction with CD44, dipeptidyl peptidaseIV, hepatocyte growth factor receptor and the SETMAR transferase, in colon cancer stem cells. Journal of Receptors and Signal Transduction, v. 33, n. 6, p. 353-358, 21 dez. 2013.

APOSTOLOU, P.; TOLOUDI, M.; PAPASOTIRIOU, I. Identification of genes involved in breast cancer and breast cancer stem cells. Breast Cancer: Targets and Therapy, v. 7, p. 183-191, 2015.

ARISMENDI-MORILLO, G. Electron microscopy morphology of the mitochondrial network in human cancer. International Journal of Biochemistry and Cell Biology, v. 41, n. 10, p. 2062-2068, 2009.

AXELSON, H. et al. Hypoxia-induced dedifferentiation of tumor cells - A mechanism behind heterogeneity and aggressiveness of solid tumors. Seminars in Cell \& Developmental Biology, v. 16, n. 4-5, p. 554-563, ago. 2005.

BAO, B. et al. Cancer Stem Cells (CSCs) and Mechanisms of Their Regulation: Implications for Cancer Therapy. National Institutes of Health, p. 1-18, 2014.

BECKER, A. et al. Extracellular Vesicles in Cancer: Cell-to-Cell Mediators of Metastasis. Cancer cell, v. 30, n. 6, p. 836-848, 12 dez. 2016.

BERTOUT, J. A.; PATEL, S. A.; SIMON, M. C. The impact of O-2 availability on human cancer. Nature Reviews Cancer, v. 8, n. 12, p. 967-975, 2008.

BIRSOY, K. et al. Metabolic determinants of cancer cell sensitivity to glucose limitation and biguanides. Nature, v. 508, n. 7494, p. 108-112, 2014.

BOARD, P. A. T. E. Breast Cancer Treatment (PDQ®). 19 out. 2018.

BOZORGI, A.; KHAZAEI, M.; KHAZAEI, M. R. Breast Cancer New Findings on Breast Cancer Stem Cells : A Review. v. 18, n. 4, p. 303-312, 2015.

BRAY, F. et al. Global cancer statistics 2018: GLOBOCAN estimates of 
incidence and mortality worldwide for 36 cancers in 185 countries. CA: a cancer journal for clinicians, v. 68, n. 6, p. 394-424, 2018.

BRENNAN, K.; BROWN, A. M. C. Is there a role for Notch signalling in human breast cancer? Breast cancer research : BCR, v. 5, n. 2, p. 69-75, 2003.

BROWN, J. M.; GIACCIA, A. J. The unique physiology of solid tumors: opportunities (and problems) for cancer therapy. Cancer research, v. 58, n. 7, p. 140816, 1 abr. 1998.

BUCK, A. et al. FDG uptake in breast cancer: Correlation with biological and clinical prognostic parameters. European Journal of Nuclear Medicine, v. 29, n. 10, p. 1317-1323, 2002.

BURKE, P. J. Mitochondria, Bioenergetics \& Apoptosis in Cancer. Trends Cancer, v. 3, n. 12, p. 857-870, 2017.

CARO-MALDONADO, A.; MUOZ-PINEDO, C. Dying for Something to Eat: How Cells Respond to Starvation. The Open Cell Signaling Journal, v. 3, p. 42-51, 14 abr. 2011.

CELIS, J. E. et al. Proteomic Characterization of the Interstitial Fluid Perfusing the Breast Tumor Microenvironment. Molecular \& Cellular Proteomics, v. 3, n. 4, p. 327-344, 2004.

CHALMIN, F. et al. Membrane-associated Hsp72 from tumor-derived exosomes mediates STAT3-dependent immunosuppressive function of mouse and human myeloidderived suppressor cells. Journal of Clinical Investigation, v. 120, n. 2, p. 457-71, 19 jan. 2010.

CHAMBERS, I. et al. Functional Expression Cloning of Nanog, a Pluripotency Sustaining Factor in Embryonic Stem Cells. Cell, v. 113, n. 5, p. 643-655, 2004.

CHEN, H.; CHAN, D. C. Mitochondrial Dynamics in Regulating the Unique Phenotypes of Cancer and Stem Cells. Cell Metabolism, v. 26, n. 1, p. 39-48, 2017.

CHENG, N.; YAO, H.; REID, L. M. Hepatic Stem Cells: Lineage Biology and Pluripotency. Principles of Regenerative Medicine, p. 344-384, 1 jan. 2008.

CHIBA, S. Concise Review: Notch Signaling in Stem Cell Systems. Stem Cells, v. 24, n. 11, p. 2437-2447, nov. 2006.

CIPOLlESCHI, M. G.; SBARBA, P. DELlO; OLIVOTTO, M. The role of hypoxia in the maintenance of hematopoietic stem cells. Blood, v. 82, n. 7, p. 2031-2037, 1993.

COSTA-SILVA, B. et al. Pancreatic cancer exosomes initiate pre-metastatic niche formation in the liver. Nature cell biology, v. 17, n. 6, p. 1-7, 2015.

COSTELLO, L. C.; FRANKLIN, R. B. The genetic/metabolic transformation concept of carcinogenesis. Cancer metastasis reviews, v. 31, n. 1-2, p. 123-30, jun. 2012.

COVELLO, K. L. et al. HIF-2 — regulates Oct-4 : effects of hypoxia on stem cell 
function, embryonic development, and tumor growth. p. 557-570, 2006.

CRONIN, K. A. et al. Annual Report to the Nation on the Status of Cancer, part I: National cancer statistics. Cancer, v. 124, n. 13, p. 2785-2800, 1 jul. 2018.

CUI, X.; HARTANTO, Y.; ZHANG, H. Advances in multicellular spheroids formation. Journal of the Royal Society, Interface, v. 14, n. 127, 2017.

CUI, Y. et al. Determination of glucose deficiency-induced cell death by mitochondrial ATP generation-driven proton homeostasis. Journal of Molecular Cell Biology, v. 9, n. 5, p. 395-408, 2017.

DAMAGHI, M. et al. Chronic acidosis in the tumour microenvironment selects for overexpression of LAMP2 in the plasma membrane. Nature Communications, v. 6, p. 1-13, 2015.

DAMAGHI, M.; WOJTKOWIAK, J. W.; GILLIES, R. J. pH sensing and regulation in cancer. Frontiers in Physiology, v. 4 DEC, n. December, p. 1-10, 2013.

DANHIER, P. et al. Cancer metabolism in space and time: Beyond the Warburg effect. Biochimica et Biophysica Acta (BBA) - Bioenergetics, v. 1858, n. 8, p. 556572, 1 ago. 2017.

DANIEL, C. et al. The role of proton dynamics in the development and maintenance of multidrug resistance in cancer. Biochimica et biophysica acta, v. 1832, n. 5, p. 606-17, 2013.

DE JONG, J.; LOOIJENGA, L. H. J. Stem Cell Marker OCT3/4 in Tumor Biology and Germ Cell Tumor Diagnostics: History and Future. Critical Reviews ${ }^{\text {TM }}$ in Oncogenesis, v. 12, n. 3-4, p. 171-203, 2006.

DEWHIRST, M. W. et al. Morphologic and hemodynamic comparison of tumor and healing normal tissue microvasculature. International journal of radiation oncology, biology, physics, v. 17, n. 1, p. 91-9, jul. 1989.

DOHERTY, J. R. et al. Targeting lactate metabolism for cancer therapeutics Find the latest version: Review series Targeting lactate metabolism for cancer therapeutics. The Journal of Clinical Investigation, v. 123, n. 9, p. 3685-3692, 2013.

DONG, L. et al. Acidosis Activation of the Proton-Sensing GPR4 Receptor Stimulates Vascular Endothelial Cell Inflammatory Responses Revealed by Transcriptome Analysis. PLoS ONE, v. 8, n. 4, 2013.

DONGRE, A.; WEINBERG, R. A. New insights into the mechanisms of epithelial-mesenchymal transition and implications for cancer. Nature Reviews Molecular Cell Biology, 20 nov. 2018.

DONTU, G. et al. Role of Notch signaling in cell-fate determination of human mammary stem/progenitor cells. Breast cancer research : BCR, v. 6, n. 6, p. R605-15, 2004.

DUPUY, F. et al. PDK1-dependent metabolic reprogramming dictates metastatic potential in breast cancer. Cell Metabolism, v. 22, n. 4, p. 577-589, 2015. 
EL ANSARI, R. et al. Altered glutamine metabolism in breast cancer; subtype dependencies and alternative adaptations. Histopathology, v. 72, n. 2, p. 183-190, 2018.

FACTS, C. Cancer facts and figures 2019. American Cancer Society, 2019.

FERLAY, J. et al. Estimating the global cancer incidence and mortality in 2018: GLOBOCAN sources and methods. International Journal of Cancer, v. 144, n. 8, p. 1941-1953, 2019.

FIASCHI, T. et al. Reciprocal metabolic reprogramming through lactate shuttle coordinately influences tumor-stroma interplay. Cancer Research, v. 72, n. 19, p. 51305140, 2012.

FIDLER, I. J.; KRIPKE, M. L.; URL, S. Metastasis Results from Preexisting Variant Cells Within a Malignant Tumor Metastasis Results from Preexisting Variant Cells Within a Malignant Tumor. Science, v. 197, n. 4306, p. 893-895, 2011.

FLAVAHAN, W. A et al. Brain tumor initiating cells adapt to restricted nutrition through preferential glucose uptake. Nature neuroscience, v. 16, n. 10, p. 1373-82, out. 2013.

FLINCK, M. et al. The acid-base transport proteins NHE1 and NBCn1 regulate cell cycle progression in human breast cancer cells. Cell Cycle, v. 17, n. 9, p. 1056-1067, 3 maio 2018.

FLINCK, M.; KRAMER, S. H.; PEDERSEN, S. F. Roles of pH in control of cell proliferation. Acta Physiologica, v. 223, n. 3, p. e13068, jul. 2018.

FRIDMAN, W. H. From Cancer Immune Surveillance to Cancer Immunoediting: Birth of Modern Immuno-Oncology. The Journal of Immunology, v. 201, n. 3, p. 825826, 1 ago. 2018.

FUNG, C. et al. Induction of Autophagy during Extracellular Matrix Detachment Promotes Cell Survival. Molecular biology of the cell, v. 19, n. 1, p. 797-806, 2008.

GANDRE-BABBE, S.; VAN DER BLIEK, A. M. The Novel Tail-anchored Membrane Protein Mff Controls Mitochondrial and Peroxisomal Fission in Mammalian Cells. Molecular Biology of the Cell, v. 19, n. 6, p. 2402-2412, jun. 2008.

GATENBY, R. A.; GILLIES, R. J. A microenvironmental model of carcinogenesis. Nature reviews. Cancer, v. 8, n. 1, p. 56-61, 2008.

GATENBY, R. A; GILLIES, R. J. Why do cancers have high aerobic glycolysis? Nature reviews. Cancer, v. 4, n. 11, p. 891-9, nov. 2004.

GATTI, S. et al. Microvesicles derived from human adult mesenchymal stem cells protect against ischaemia-reperfusion-induced acute and chronic kidney injury. Nephrology Dialysis Transplantation, v. 26, n. 5, p. 1474-1483, 1 maio 2011.

GAWLOWSKI, T. et al. Modulation of dynamin-related protein 1 (DRP1) function by increased O-linked- $\beta$-N-acetylglucosamine modification (O-GlcNAc) in cardiac myocytes. The Journal of biological chemistry, v. 287, n. 35, p. 30024-34, 24 ago. 2012. 
GERWECK, L. E.; SEETHARAMAN, K. Cellular pH Gradient in Tumor versus Normal Tissue : Potential Exploitation for the Treatment of Cancer Advances in Brief Cellular pH Gradient in Tumor versus Normal Tissue: Potential Exploitation for the Treatment of Cancer1. p. 1194-1198, 1996.

GILLIES, R. J. et al. MRI of the tumor microenvironment. Journal of Magnetic Resonance Imaging, v. 16, n. 4, p. 430-450, 2002.

GLUNDE, K. et al. Extracellular Acidification Alters Lysosomal Trafficking in Human Breast Cancer Cells 1. Neoplasia, v. 5, n. 6, p. 533-545, 2003.

GMBH, R. D. The Multiple Roles of Exosomes in Metastasis. v. 16, 2017.

GRIFFITHS, J. R. Are cancer cells acidic? British journal of cancer, v. 64, n. 3, p. 425-7, set. 1991.

GROSSE-WILDE, A. et al. Stemness of the hybrid epithelial/mesenchymal state in breast cancer and its association with poor survival. PLoS ONE, v. 10, n. 5, p. 1-28, 2015.

GUAITA, S. et al. Snail induction of epithelial to mesenchymal transition in tumor cells is accompanied by MUC1 repression and ZEB1 expression. Journal of Biological Chemistry, v. 277, n. 42, p. 39209-39216, 2002.

GUHA, M. et al. Mitochondrial retrograde signaling induces epithelialmesenchymal transition and generates breast cancer stem cells. Oncogene, v. 33, n. 45, p. 5238-5250, 4 nov. 2014.

GUSTAFSSON, M. V. et al. Hypoxia requires Notch signaling to maintain the undifferentiated cell state. Developmental Cell, v. 9, n. 5, p. 617-628, 2005.

GWANGWA, M. V.; JOUBERT, A. M.; VISAGIE, M. H. Effects of glutamine deprivation on oxidative stress and cell survival in breast cell lines. Biological Research, v. 52, n. 1, p. 15, 2019.

HAN, X.-J. et al. Mitochondrial dynamics regulates hypoxia-induced migration and antineoplastic activity of cisplatin in breast cancer cells. International Journal of Oncology, v. 46, n. 2, p. 691-700, 1 fev. 2015.

HANAHAN, D.; WEINBERG, R. A. Hallmarks of cancer: the next generation. Cell, v. 144, n. 5, p. 646-74, 2011.

HELMLINGER, G. et al. Interstitial $\mathrm{pH}$ and $\mathrm{pO} 2$ gradients in solid tumors in vivo: high-resolution measurements reveal a lack of correlation. Nature Medicine, v. 3, n. 2, p. 177-182, 1997.

HENNIGHAUSEN, L.; ROBINSON, G. W. Information networks in the mammary gland. Nature Reviews Molecular Cell Biology, v. 6, n. 9, p. 715-725, 2005.

HERREROS-VILLANUEVA, M. et al. SOX2 promotes dedifferentiation and imparts stem cell-like features to pancreatic cancer cells. Oncogenesis, v. 2, n. 8, p. e61$12,2013$.

HERSCHKOWITZ, J. I. et al. Identification of conserved gene expression 
features between murine mammary carcinoma models and human breast tumors. Genome biology, v. 8, n. 5, p. R76, jan. 2007.

HJELMELAND, A B. et al. Acidic stress promotes a glioma stem cell phenotype. Cell death and differentiation, v. 18, n. 5, p. 829-40, maio 2011.

HODGE, D. R.; HURT, E. M.; FARRAR, W. L. The role of IL-6 and STAT3 in inflammation and cancer. European Journal of Cancer, v. 41, n. 16, p. 2502-2512, nov. 2005.

HOPPINS, S.; LACKNER, L.; NUNNARI, J. The Machines that Divide and Fuse Mitochondria. Annual Review of Biochemistry, v. 76, n. 1, p. 751-780, 2007.

HUANG, J.; LI, H.; REN, G. Epithelial-mesenchymal transition and drug resistance in breast cancer (Review)International Journal of OncologySpandidos Publications, , 1 set. 2015. Disponível em: <https://www.spandidospublications.com/10.3892/ijo.2015.3084>. Acesso em: 5 dez. 2018

ILIOPOULOS, D. et al. Inducible formation of breast cancer stem cells and their dynamic equilibrium with non-stem cancer cells via IL6 secretion. Proceedings of the National Academy of Sciences, v. 108, n. 4, p. 1397-1402, 25 jan. 2011.

INCA. Estimativa 2018. Incidencia de cáncer no Brasil. [s.l: s.n.].

IZUMI, H. et al. Cellular $\mathrm{pH}$ regulators: Potentially promising molecular targets for cancer chemotherapy. Cancer Treatment Reviews, v. 29, n. 6, p. 541-549, 2003.

JAMES, D. I. et al. hFis1, a Novel Component of the Mammalian Mitochondrial Fission Machinery. Journal of Biological Chemistry, v. 278, n. 38, p. 36373-36379, 19 set. 2003.

JAYATILAKA, H. et al. Synergistic IL-6 and IL-8 paracrine signalling pathway infers a strategy to inhibit tumour cell migration. Nature Communications, v. 8, p. 15584, 26 maio 2017.

JIN, L. et al. Expression of interleukin-1beta in human breast carcinoma. Cancer, v. 80, n. 3, p. 421-34, 1 ago. 1997.

JUNG, C. H. et al. mTOR regulation of autophagy. FEBS Letters, v. 584, n. 7, p. 1287-1295, 2010.

JUSTUS, C. R.; DONG, L.; YANG, L. V. Acidic tumor microenvironment and $\mathrm{pH}$-sensing $\mathrm{G}$ protein-coupled receptors. Frontiers in Physiology, v. 4 DEC, n. December, p. 1-9, 2013.

KABEYA, Y. et al. LC3, a mammalian homologue of yeast Apg8p, is localized in autophagosome membranes after processing. EMBO journal, v. 19, n. 21, p. 57205728, 2000.

KALLURI, R.; WEINBERG, R. A. Review series The basics of epithelialmesenchymal transition. Journal of Clinical Investigation, v. 119, n. 6, p. 1420-1428, 2009.

KATAJISTO, P. et al. Asymmetric apportioning of aged mitochondria between 
daughter cells is required for stemness. Science, v. 348, n. 6232, p. 340-343, 2015.

KATO, Y. et al. Acidic extracellular microenvironment and cancer. Cancer cell international, v. 13, n. 1, p. 89, 2013.

KEITH, B.; SIMON, M. C. Hypoxia Inducible Factors, stem cells and cancer. v. 129, n. 3, p. 465-472, 2007.

KENNEDY, K. M. et al. Catabolism of Exogenous Lactate Reveals It as a Legitimate Metabolic Substrate in Breast Cancer. PLoS ONE, v. 8, n. 9, p. 1-20, 2013.

$\mathrm{KHACHO}$, M. et al. Acidosis overrides oxygen deprivation to maintain mitochondrial function and cell survival. Nature Communications, v. 5, n. 1, p. 3550, 1 dez. 2014.

KHARAZIHA, P. et al. Tumor cell-derived exosomes: A message in a bottle. Biochimica et Biophysica Acta - Reviews on Cancer, v. 1826, n. 1, p. 103-111, 2012.

KLIONSKY, D. J. et al. Guidelines for the use and interpretation of assays for monitoring autophagy. Autophagy, v. 8, n. 4, p. 445-544, abr. 2012.

KNOTT, A. B. et al. Mitochondrial fragmentation in neurodegeneration. Nature reviews. Neuroscience, v. 9, n. 7, p. 505-18, jul. 2008.

KONG, D. et al. Cancer stem cells and Epithelial-to-Mesenchymal Transition (EMT)-Phenotypic Cells: Are they Cousins or Twins? Cancers, v. 3, n. 1, p. 716-729, 2011.

KUMAR, S. M. et al. Acquired cancer stem cell phenotypes through Oct4mediated dedifferentiation. oncogene, v. 31, n. 47, p. 4898-4911, 2012.

KUO, M. C. et al. Cancer stemness in bone marrow micrometastases of human breast cancer. Surgery, v. 163, n. 2, p. 330-335, 1 fev. 2018.

LAMOUILLE, S.; XU, J.; DERYNCK, R. Molecular mechanisms of epithelialmesenchymal transition. National Review Molecular Cell Biology, v. 15, n. 3, p. 178196, 2014.

LARUE, L.; BELLACOSA, A. 2005. Epithelial-mesenchymal transition in development and cancer: role of phosphatidylinositol 30 kinase/AKT pathways. Oncogene, n. 24, p. 7443-7454, 2005.

LE GRAND, F. et al. Wnt7a Activates the Planar Cell Polarity Pathway to Drive the Symmetric Expansion of Satellite Stem Cells. Cell Stem Cell, v. 4, n. 6, p. 535-547, 5 jun. 2009.

LEFORT, S. et al. Inhibition of autophagy as a new means of improving chemotherapy efficiency in high-LC3B triple-negative breast cancers. Autophagy, v. 10, n. 12, p. 2122-2142, 2014.

LEGROS, F. et al. Mitochondrial Fusion in Human Cells Is Efficient, Requires the Inner Membrane Potential, and Is Mediated by Mitofusins. Molecular Biology of the Cell, v. 13, n. 12, p. 4343-4354, dez. 2002.

LEHUÉDÉ, C. et al. Metabolic plasticity as a determinant of tumor growth and 
metastasis. Cancer Research, v. 76, n. 18, p. 5201-5208, 2016.

LEWIS, C.; MURDOCH, C. Macrophage Responses to Hypoxia. The American Journal of Pathology, v. 167, n. 3, p. 627-635, set. 2005.

LI, L. et al. Collective cell migration: Implications for wound healing and cancer invasion. Burns \& Trauma, v. 1, n. 1, p. 21, 2013.

LI, X.-F.; O'DONOGHUE, J. A. Hypoxia in microscopic tumors. Cancer letters, v. 264, n. 2, p. 172-80, 18 jun. 2008.

LIM, B.; HORTOBAGYI, G. N. Current challenges of metastatic breast cancer. Cancer and Metastasis Reviews, v. 35, n. 4, p. 495-514, 2016.

LIM, E. et al. Transcriptome analyses of mouse and human mammary cell subpopulations reveal multiple conserved genes and pathways. Breast cancer research : BCR, v. 12, n. 2, p. R21, jan. 2010.

LIMOGE, M. et al. Tumor-fibroblast interactions stimulate tumor vascularization by enhancing cytokine-driven production of MMP9 by tumor cells. Oncotarget, v. 8, n. 22, p. 35592-35608, 2017.

LINDEMAN, G. J.; VISVADER, J. E. Insights into the cell of origin in breast cancer and breast cancer stem cells. Asia-Pacific Journal of Clinical Oncology, v. 6, n. 2, p. 89-97, 2010.

LOGOZZI, M. et al. Increased PSA expression on prostate cancer exosomes in in vitro condition and in cancer patients. Cancer Letters, v. 403, p. 318-329, 10 set. 2017.

LOPEZ-SÁNCHEZ, L. M. et al. CoCl2, a mimic of hypoxia, induces formation of polyploid giant cells with stem characteristics in colon cancer. PLoS ONE, v. 9, n. 6, 2014.

LOUIE, E. et al. Identification of a stem-like cell population by exposing metastatic breast cancer cell lines to repetitive cycles of hypoxia and reoxygenation. Breast Cancer Research, v. 12, n. 6, p. R94, 2010.

LU, H. et al. Regulation and function of mitophagy in development and cancer. Autophagy, v. 9, n. 11, p. 1720-1736, 2013.

LU, X. et al. The pluripotency factor nanog promotes breast cancer tumorigenesis and metastasis. Oncogene, v. 33, n. 20, p. 2655-2664, 2014.

MAHONEY, B. P. et al. Tumor acidity, ion trapping and chemotherapeutics: I. Acid $\mathrm{pH}$ affects the distribution of chemotherapeutic agents in vitro. Biochemical Pharmacology, v. 66, n. 7, p. 1207-1218, 2003.

MANI, S. A et al. The epithelial-mesenchymal transition generates cells with properties of stem cells. Cell, v. 133, n. 4, p. 704-715, 2008.

MARCINKOWSKA, M.; STAŃCZYK, M.; KLAJNERT-MACULEWICZ, B. [Trastuzumab - a monoclonal antibody - and dendrimers in a targeted therapy for breast cancer]. Postẹpy higieny i medycyny doświadczalnej (Online), v. 69, p. 1313-24, 2015. 
MARIE-CALINE Z. ABADJIAN, W. BARRY EDWARDS, AND C. J. A. Imaging the Tumor Microenvironment. p. 221-228, 2012.

MARTINEZ-OUTSCHOORN, U. E. et al. Cancer metabolism: A therapeutic perspective. Nature Reviews Clinical Oncology, v. 14, n. 1, p. 11-31, 2017.

MATTHEW G. VANDER HEIDEN, LEWIS C. CANTLEY, C. B. T. Understanding the Warburg effect: the metabolic requirements of cell proliferation. science, v. 324, n. 5930, p. 1029-1033, 2010.

MIHAYLOVA, M. M.; SABATINI, D. M.; YILMAZ, Ö. H. Dietary and metabolic control of stem cell function in physiology and cancer. Cell stem cell, v. 14, n. 3, p. 292-305, 6 mar. 2014.

MIKKERS, H.; FRISÉN, J. Deconstructing stemness. EMBO Journal, v. 24, n. 15, p. 2715-2719, 2005.

MINA, M. et al. Conditional Selection of Genomic Alterations Dictates Cancer Evolution and Oncogenic Dependencies. Cancer Cell, v. 32, n. 2, p. 155- 168.e6, 2017.

MJIYAD, N. EL et al. Sugar-free approaches to cancer cell killing. Oncogene, v. 30, p. 253-264, 2011.

MORITA, T. et al. Clastogenicity of low $\mathrm{pH}$ to various cultured mammalian cells. Mutation Research - Fundamental and Molecular Mechanisms of Mutagenesis, v. 268, n. 2, p. 297-305, 1992.

MORUNO, F.; PÉREZ-JIMÉNEZ, E.; KNECHT, E. Regulation of Autophagy by Glucose in Mammalian Cells. Cells, v. 1, n. 3, p. 372-395, 2012.

MOU, W. et al. Expression of Sox 2 in breast cancer cells promotes the recruitment of M2 macrophages to tumor microenvironment. Cancer Letters, v. 358, n. 2, p. 115123, 28 mar. 2015.

MUKHERJEE, P. et al. Modulation of SOX2 expression delineates an end-point for paclitaxel-effectiveness in breast cancer stem cells. Scientific Reports, v. 7, n. 1, p. $1-16,2017$.

MÜlLER, G. A.; RODEMANN, H. P. Characterization of human renal fibroblasts in health and disease: I. Immunophenotyping of cultured tubular epithelial cells and fibroblasts derived from kidneys with histologically proven interstitial fibrosis. American journal of kidney diseases : the official journal of the National Kidney Foundation, v. 17, n. 6, p. 680-3, jun. 1991.

MURAKAMI, S. et al. SRY and OCT4 Are Required for the Acquisition of Cancer Stem Cell-Like Properties and Are Potential Differentiation Therapy Targets. STEM CELLS, v. 33, n. 9, p. 2652-2663, 1 set. 2015.

NAKAGAWA, Y. et al. Effects of extracellular $\mathrm{pH}$ and hypoxia on the function and development of antigen-specific cytotoxic T lymphocytes. Immunology Letters, v. 167, n. 2, p. 72-86, 1 out. 2015.

NAKAZAWA, M. S.; KEITH, B.; SIMON, M. C. Oxygen availability and metabolic adaptations. Nature Reviews Cancer, v. 16, n. 10, p. 663-673, 2016 a. 
NAKAZAWA, M. S.; KEITH, B.; SIMON, M. C. Oxygen availability and metabolic adaptations. Nature Reviews Cancer, v. 16, n. 10, p. 663-673, 1 out. 2016b.

NAMEE, N. M.; O’DRISCOLL, L. Extracellular vesicles and anti-cancer drug resistance. Biochimica et Biophysica Acta (BBA) - Reviews on Cancer, v. 1870, n. 2, p. 123-136, 1 dez. 2018.

NERI, D.; SUPURAN, C. T. Interfering with $\mathrm{pH}$ regulation in tumours as a therapeutic strategy. Nature reviews. Drug discovery, v. 10, n. 10, p. 767-77, 2011.

NIETO, M. A. the Snail Superfamily of Zinc-Finger Transcription Factors. Nature Reviews Molecular Cell Biology, v. 3, n. 3, p. 155-166, 2002.

NING, Y. et al. Interleukin-8 is associated with proliferation, migration, angiogenesis and chemosensitivity in vitro and in vivo in colon cancer cell line models. International Journal of Cancer, v. 128, n. 9, p. 2038-2049, 1 maio 2011.

NOWELL, P. C. The Clonal Evolution of Tumor Cell Populations. science, v. 194, n. 1, p. 23-28, 1976.

ODLE, T. G. Precision Medicine in Breast Cancer Care. Radiology technology, v. 88, n. 4, p. 401-424, 2017.

OLSSON, E. et al. CD44 isoforms are heterogeneously expressed in breast cancer and correlate with tumor subtypes and cancer stem cell markers. BMC Cancer, v. 11, n. 1, p. 418, 2011.

OTTO WARBURG, B.; WIND, F.; NEGELEIN, N. The metabolism of tumours in the body. Biochem. Z. Biochem. Z. Biochem. Z.. Biol. Chem, v. 309, n. 2, p. 397$519,1923$.

PAOLICCHI, E. et al. Targeting hypoxic response for cancer therapy HYPOXIA AND THERAPEUTIC TARGETS. Oncotarget, v. 7, n. 12, 2016.

PAROLINI, I. et al. Microenvironmental $\mathrm{pH}$ is a key factor for exosome traffic in tumor cells. The Journal of biological chemistry, v. 284, n. 49, p. 34211-22, 4 dez. 2009.

PAVLIDES, S. et al. The reverse Warburg effect: Aerobic glycolysis in cancer associated fibroblasts and the tumor stroma. Cell Cycle, v. 8, n. 23, p. 3984-4001, 2009.

PAVLOVA, N. N.; THOMPSON, C. B. THE EMERGING HALLMARKS OF CANCER METABOLISM. Cell Metab, v. 23, n. 1, p. 27-47, 2016.

PEAIRS, K. S. et al. Screening for Breast Cancer. [s.1.] Elsevier, 2017. v. 55

PECE, S. et al. Biological and molecular heterogeneity of breast cancers correlates with their cancer stem cell content. Cell, v. 140, n. 1, p. 62-73, 8 jan. 2010.

PEINADO, H.; OLMEDA, D.; CANO, A. Snail, Zeb and bHLH factors in tumour progression: an alliance against the epithelial phenotype? Nature Reviews Cancer, v. 7, n. 6, p. $415-428,2007$.

PEPPICELLI, S. et al. Contribution of acidic melanoma cells undergoing epithelial-to-mesenchymal transition to aggressiveness of non-acidic melanoma cells. 
Clinical \& Experimental Metastasis, v. 31, n. 4, p. 423-433, 28 abr. 2014.

PEPPICELLI, S. et al. Extracellular acidity strengthens mesenchymal stem cells to promote melanoma progression. Cell cycle (Georgetown, Tex.), v. 14, n. 19, p. 3088$100,2015$.

PEPPICELLI, S. et al. Acidity of Microenvironment as a Further Driver of Tumor Metabolic Reprogramming. Journal of Clinical \& Cellular Immunology, v. 08, n. 01, p. 1-5, 2017a.

PEPPICELLI, S. et al. The acidic microenvironment as a possible niche of dormant tumor cells. Cellular and Molecular Life Sciences, v. 0, n. 0, p. 0, $2017 \mathrm{~b}$.

PETERSEN, C. et al. MCT1 and MCT4 Expression and Lactate Flux Activity Increase during White and Brown Adipogenesis and Impact Adipocyte Metabolism. Scientific Reports, v. 7, n. 1, p. 1-13, 2017.

PFAFFL, M. W. A new mathematical model for relative quantification in realtime RT-PCR. Nucleic Acids Research, v. 29, n. 9, p. 45e - 45, 1 maio 2001.

PILLAI, S. R. et al. Causes, consequences, and therapy of tumors acidosis. Cancer and Metastasis Reviews, v. 1, 2019.

PIVA, M. et al. Sox 2 promotes tamoxifen resistance in breast cancer cells. EMBO Molecular Medicine, v. 6, n. 1, p. 66-79, jan. 2014.

POON, E.; HARRIS, A. L.; ASHCROFT, M. Targeting the hypoxia-inducible factor (HIF) pathway in cancer. Expert reviews in molecular medicine, v. 11, n. August, p. e26, jan. 2009.

PRUD'HOMME, G. J. Cancer stem cells and novel targets for antitumor strategies. Current pharmaceutical design, v. 18, n. 19, p. 2838-49, 2012.

QIU, S.-Q. et al. Tumor-associated macrophages in breast cancer: Innocent bystander or important player? Cancer Treatment Reviews, v. 70, p. 178-189, nov. 2018.

QUAIL, D. F.; JOYCE, J. A. Microenvironmental regulation of tumor progression and metastasis. Nature medicine, v. 19, n. 11, p. 1423-37, nov. 2013.

RAGHUNAND, N.; GILLIES, R. J. pH and drug resistance in tumors. Drug resistance updates : reviews and commentaries in antimicrobial and anticancer chemotherapy, v. 3, n. 1, p. 39-47, 2000.

RAICHAND, S. et al. Conclusions in systematic reviews of mammography for breast cancer screening and associations with review design and author characteristics. Systematic Reviews, v. 6, n. 1, p. 1-8, 2017.

RAKHA, E. A.; CHAN, S. Metastatic Triple-negative Breast Cancer. Clinical Oncology, v. 23, n. 9, p. 587-600, 2011.

RAMÍREZ-PEINADO, S. et al. Glucose-starved Cells Do Not Engage in Prosurvival Autophagy. Journal of Biological Chemistry, v. 288, n. 42, p. 3038730398, 2013. 
RATAJCZAK, J. et al. Embryonic stem cell-derived microvesicles reprogram hematopoietic progenitors: evidence for horizontal transfer of mRNA and protein delivery. Leukemia, v. 20, n. 5, p. 847-856, 2 maio 2006.

REYA, T. et al. Stem cells, cancer, and cancer stem cells. v. 414, n. November, p. $105-111,2001$.

RICARDO, S. et al. Breast cancer stem cell markers CD44, CD24 and ALDH1: expression distribution within intrinsic molecular subtype. Journal of Clinical Pathology, v. 64, n. 11, p. 937-946, 1 nov. 2011.

RISS, T. L. et al. Cell Viability Assays. [s.1.] Eli Lilly \& Company and the National Center for Advancing Translational Sciences, 2004.

ROMERO, I. L. et al. Molecular pathways: trafficking of metabolic resources in the tumor microenvironment. Clinical cancer research : an official journal of the American Association for Cancer Research, v. 21, n. 4, p. 680-6, 15 fev. 2015.

ROMITO, A.; COBELLIS, G. Pluripotent stem cells: Current understanding and future directions. Stem Cells International, v. 2016, n. Icm, 2016.

RØNNOV-JESSEN, L.; PETERSEN OW. A function for filamentous alphasmooth muscle actin: retardation of motility in fibroblasts. journal cell biology, v. 134, n. 1, p. 67-80, 1996.

ROTHBERG, J. M. et al. Acid-mediated tumor proteolysis: contribution of cysteine cathepsins. Neoplasia (New York, N.Y.), v. 15, n. 10, p. 1125-37, 2013.

ROTIN, D. et al. Requirement of the $\mathrm{Na}+\mathrm{H}+$ exchanger for tumor growth. Cancer research, v. 49, n. 1, p. 205-11, 1 jan. 1989.

ROZHIN, J. et al. Pericellular pH Affects Distribution and Secretion of Cathepsin B in Malignant Cells. Cancer Research, v. 54, n. 24, p. 6517-6525, 1994.

SAN-MILLÁN, I.; BROOKS, G. A. Reexamining cancer metabolism: Lactate production for carcinogenesis could be the purpose and explanation of the Warburg Effect. Carcinogenesis, v. 38, n. 2, p. 119-133, 2017.

SÁNCHEZ-TILLÓ, E. et al. ZEB1 represses E-cadherin and induces an EMT by recruiting the SWI/SNF chromatin-remodeling protein BRG1. Oncogene, v. 29, n. 24, p. 3490-3500, 2010.

SEMENZA, G. L. HIF-1 mediates metabolic responses to intratumoral hypoxia and oncogenic mutations. Journal of Clinical Investigation, v. 123, n. 9, p. 3664-3671, 2013.

SERRATİ, S. et al. Next-generation sequencing: advances and applications in cancer diagnosis. OncoTargets and Therapy, p. 7355-7365, 2016.

SEYFRIED, T. N. et al. Cancer as a metabolic disease: Implications for novel therapeutics. Carcinogenesis, v. 35, n. 3, p. 515-527, 2014.

SHIPITSIN, M. et al. Molecular Definition of Breast Tumor Heterogeneity. Cancer Cell, v. 11, n. 3, p. 259-273, 2007. 
SIEGEL, R. L.; MILLER, K. D.; JEMAL, A. Cancer statistics, 2019. CA: A Cancer Journal for Clinicians, v. 69, n. 1, p. 7-34, jan. 2019.

SILVA, T. A. et al. AHNAK enables mammary carcinoma cells to produce extracellular vesicles that increase neighboring fibroblast cell motility. Oncotarget, v. 7, n. 31, p. 49998-50016, 2 ago. 2016.

SIMIAN, M. et al. The interplay of matrix metalloproteinases, morphogens and growth factors is necessary for branching of mammary epithelial cells. Development (Cambridge, England), v. 128, n. 16, p. 3117-31, ago. 2001.

SINGH, B. et al. Selection of metastatic breast cancer cells based on adaptability of their metabolic state. PLoS ONE, v. 7, n. 5, 2012.

SMALLEY, K. S. M. Understanding melanoma signaling networks as the basis for molecular targeted therapy. The Journal of investigative dermatology, v. 130, n. 1, p. 28-37, jan. 2010.

SMALLEY, M.; ASHWORTH, A. Stem cells and breast cancer: A field in transit. Nature Reviews Cancer, v. 3, n. 11, p. 832-844, nov. 2003.

SMIRNOVA, E. et al. Dynamin-related Protein Drp1 Is Required for Mitochondrial Division in Mammalian Cells. Molecular Biology of the Cell, v. 12, n. 8, p. 2245-2256, ago. 2001.

SRINIVASAN, S. et al. Mitochondrial dysfunction and mitochondrial dynamicsThe cancer connection. Biochimica et Biophysica Acta - Bioenergetics, v. 1858, n. 8, p. 602-614, 2017.

STERNECKERT, J.; HÖING, S.; SCHÖLER, H. R. Concise Review: Oct4 and More: The Reprogramming Expressway. STEM CELLS, v. 30, n. 1, p. 15-21, 1 jan. 2012.

STUBBS, M. et al. Causes and consequences of tumour acidity and implications for treatment. Molecular Medicine Today, v. 6, n. 1, p. 15-19, 2000.

SULLIVAN, N. J. et al. Interleukin-6 induces an epithelial-mesenchymal transition phenotype in human breast cancer cells. Oncogene, v. 28, n. 33, p. 2940-2947, 6 ago. 2009.

SUN, L. et al. Metabolic reprogramming for cancer cells and their microenvironment: Beyond the Warburg Effect. Biochimica et Biophysica Acta Reviews on Cancer, v. 1870, n. 1, p. 51-66, 2018.

TAKAHASHI, K. et al. Induction of pluripotent stem cells from adult human fibroblasts by defined factors. Cell, p. 861-872, 2007.

THIERY, J. P. et al. Epithelial-Mesenchymal Transitions in Development and Disease. Cell, v. 139, n. 5, p. 871-890, 2009.

THOMLINSON, R. H. Tumour anoxia and the response to radiation. The Scientific basis of medicine annual reviews, p. 74-90, 1965.

TODD, L. R. et al. Growth Factor ervl -like Modulates Drp1 to Preserve 
Mitochondrial Dynamics and Function in Mouse Embryonic Stem Cells. Molecular Biology of the Cell, v. 21, n. 7, p. 1225-1236, 1 abr. 2010.

U.S. NATIONAL LIBRARY OF MEDICINE. Completed, Terminated Studies | Breast Cancer - List Results - ClinicalTrials.gov. Disponível em: $<$ https://clinicaltrials.gov/ct2/results? cond $=$ Breast + Cancer\&term $=\&$ cntry $=\&$ state $=\&$ city $=\&$ dist $=\&$ Search $=$ Search\&recrs $=$ e $\&$ recrs $=\mathrm{h}>$. Acesso em: 30 abr. 2019.

UENO, T. et al. Characteristic Gene Expression Profiles of Human Fibroblasts and Breast Cancer Cells in a Newly Developed Bilateral Coculture System. BioMed Research International, v. 2015, p. 1-11, 2015.

VAN GISBERGEN, M. W. et al. How do changes in the mtDNA and mitochondrial dysfunction influence cancer and cancer therapy? Challenges, opportunities and models. Mutation Research - Reviews in Mutation Research, v. 764, p. 16-30, 2015.

VAUPEL, P.; RALLINOÂ, F.; OKUNIEFF, P. Review Blood Flow , Oxygen and Nutrient Supply, and Metabolic Microenvironment Human Tumors: A Review1.p. 6449-6465, 1989. 2011.

VISVADER, J. E. Cells of origin in cancer. Nature, v. 469, n. 7330, p. 314-322,

VON AHRENS, D. et al. The role of stromal cancer-associated fibroblasts in pancreatic cancer. Journal of Hematology and Oncology, v. 10, n. 1, p. 1-8, 2017.

WALLACE, D. C. Mitochondrial and cancer. Nat Rev Cancer, v. 12, n. 10, p. 685-698, 2015.

WANG, G. L. et al. Hypoxia-inducible factor 1 is a basic-helix-loop-helix-PAS heterodimer regulated by cellular O2 tension. Proceedings of the National Academy of Sciences of the United States of America, v. 92, n. 12, p. 5510-4, 6 jun. 1995.

WANG, G. L.; SEMENZA, G. L. Purification and characterization of hypoxiainducible factor 1. The Journal of biological chemistry, v. 270, n. 3, p. 1230-7, 20 jan. 1995.

WANG, Y. et al. Coordinative metabolism of glutamine carbon and nitrogen in proliferating cancer cells under hypoxia. Nature Communications, v. 10, n. 1, p. 201, 14 dez. 2019.

WARE, M. J. et al. Generation of homogenous 3D pancreatic cancer cell spheroids using an improved hanging drop technique. Tissue engineering. Part $\mathbf{C}$, Methods, p. 1-36, 2016.

WILDE, L. et al. Metabolic coupling and the Reverse Warburg Effect in cancer: Implications for novel biomarker and anticancer agent development. Seminars in Oncology, v. 44, n. 3, p. 198-203, 2017.

WILLMS, E. et al. Extracellular Vesicle Heterogeneity: Subpopulations, Isolation Techniques, and Diverse Functions in Cancer Progression. Frontiers in immunology, v. 9, p. 738, 2018. 
WISE, D. R. et al. Hypoxia promotes isocitrate dehydrogenase-dependent carboxylation of $\alpha$-ketoglutarate to citrate to support cell growth and viability. Proceedings of the National Academy of Sciences of the United States of America, v. 108, n. 49, p. 19611-6, 6 dez. 2011.

WOBUS, A. M.; BOHELER, K. R. Embryonic Stem Cells: Prospects for Developmental Biology and Cell Therapy. Physiological Reviews, v. 85, n. 2, p. 635678, abr. 2005.

WOJTKOWIAK, J. W. et al. Chronic Autophagy Is a Cellular Adaptation to Tumor Acidic pH Microenvironments. Cancer research, v. 72, n. 16, p. 3938-3948, 2012.

XING, F.; SAIDOU, J.; WATABE, K. Cancer associated fibroblasts (CAFs) in tumor microenvironment. Frontiers in bioscience (Landmark edition), v. 15, p. 16679, 1 jan. 2010.

YEO, J. C.; NG, H. H. The transcriptional regulation of pluripotency. Cell Research, v. 23, n. 1, p. 20-32, 2013.

YU, J. et al. Induced pluripotent stem cell lines derived from human somatic cells. Science (New York, N.Y.), v. 318, n. 5858, p. 1917-20, 21 dez. 2007. $2151,2012$.

YUA, Z. et al. Cancer Stem Cells. Int J Biochem Cell Biol, v. 44, n. 12, p. 2144

ZAMARRON, B. F.; CHEN, W. Dual roles of immune cells and their factors in cancer development and progression. International journal of biological sciences, v. 7, n. 5, p. 651-8, 2011.

ZHANG, S. et al. Generation of cancer stem-like cells through the formation of polyploid giant cancer cells. Oncogene, v. 33, n. 1, p. 116-128, 2013.

ZHAO, H. et al. Tumor microenvironment derived exosomes pleiotropically modulate cancer cell metabolism. eLife, v. 5, p. 1-27, 2016.

ZHAO, J. et al. Mitochondrial dynamics regulates migration and invasion of breast cancer cells. Oncogene, v. 32, n. 40, p. 4814-4824, 2013.

ZHAO, Z. et al. Stromal-epithelial metabolic coupling in gastric cancer: Stromal MCT4 and mitochondrial TOMM20 as poor prognostic factors. European Journal of Surgical Oncology, v. 40, n. 10, p. 1361-1368, 2014.

ZHU, S. et al. ASIC1 and ASIC3 contribute to acidity-induced EMT of pancreatic cancer through activating Ca2+/RhoA pathway. Cell Death and Disease, v. 8, n. 5, p. e2806, 18 maio 2017. 